\title{
COTO DE LA ISLETA (CHICLANA, CÁDIZ). NUEVOS DATOS Y PERSPECTIVAS SOBRE EL POBLAMIENTO ROMANO DE LA ZONA SUR DE LA BAHÍA DE CÁDIZ
}

\section{COTO DE LA ISLETA (CHICLANA, CÁDIZ). NEW DATA AND PERSPECTIVES ON THE ROMAN SETTLEMENT PATTERN IN THE SOUTHERN AREA OF THE BAY OF CÁDIZ}

\author{
ANTONIO M. SÁEZ ROMERO \\ Departamento de Prehistoria y Arqueología, Facultad de Geografía e Historia, Universidad de Sevilla. \\ Correo-e: asaez1@us.es. ORCID: https://orcid.org/0000-0001-7071-9748. \\ FRANCISCO CARRERO RAMÍREZ \\ Arqueólogo. Avenida Augusta Julia s/n 11011 Cádiz, España \\ Correo-e: paco.carrero@gmail.com. ORCID: https://orcid.org/0000-0003-4135-0851
}

\begin{abstract}
Resumen: A pesar de su ubicación inmediata a la desembocadura meridional del caño de Sancti Petri y al islote homónimo, una zona vital desde la perspectiva histórica y geoarqueológica en el marco de la bahía gaditana, el estudio del resto de las marismas y yacimientos arqueológicos del tramo sur del caño ha sido escaso hasta el momento. En este trabajo se retoma su análisis aportando nuevos datos sobre el poblamiento de la zona en la Antigüedad, a partir de la discusión de nuevas evidencias disponibles para el caso de Coto de la Isleta, identificada desde hace décadas como una posible cetaria romana. El examen de la topografía del yacimiento y de nuevas evidencias materiales dejadas al descubierto por la erosión costera permiten proponer una reinterpretación de esta supuesta función pesquero-conservera y una posible relación con el topónimo Ad Herculem.
\end{abstract}

Palabras clave: Geoarqueología, Cetariae, Villae, Mosaico, Gades, Marismas, Salinas.

\begin{abstract}
Despite its immediate location at the southern mouth of the Sancti Petri Channel and the homonymous islet, a critical area from the historical and geoarchaeological perspective in the bay of Cadiz, the study of the evolution of the marshes and archaeological sites of the southern section of the channel has been scarce so far. In this paper the analysis is resumed, providing new data on the settlement pattern in the area in Antiquity based on the discussion of new evidence available for the case of Coto de la Isleta, identified for decades as a Roman cetaria. The examination of the topography of the site and new material evidence exposed by coastal erosion allow us to reinterpret the function of this hypothetical fish-processing facility and propose a possible relation with the place-name Ad Herculem.
\end{abstract}

Keywords: Geoarchaeology, Cetariae, Villae, Mosaic, Gades, marshlands, Salt-works. 


\section{INTRODUCCIÓN}

El actual caño de Sancti Petri y los sistemas de marismas que lo enmarcan debieron constituir, desde su consolidación como hito geográfico en la época prerromana, uno de los principales escenarios de actividad económica de la mitad meridional de la bahía de Cádiz en relación al tráfico marítimo, el comercio y la explotación de recursos marinos. Tampoco debe perderse de vista la proximidad del templo dedicado a la divinidad tutelar de la ciudad de Gadir/Gades, un santuario de Melqart-Hércules Gaditanus que estuvo ubicado -como señalan Estrabón (III, 5, 3) y otros autores clásicos- en el extremo sur de la isla gaditana y que fue referencia internacional durante toda la Antigüedad (Avieno, Ora Maritima, 82-87). A pesar del enorme interés de esta zona para el análisis no solo del asentamiento antiguo gaditano, sino en general de múltiples aspectos de la historia de la región, ha sido verdaderamente escasa la atención recibida por las notables extensiones que rodean estos parajes, caracterizadas por una intrincada red de marismas y caños en parte alterados por la labra, en época moderna, de salinas y otras estructuras típicas del paisaje actual de la bahía gaditana (esteros para piscifactorías, instalaciones almadraberas, etc.). En los últimos años ha sido posible recopilar nuevos datos acerca de yacimientos de época púnica y romana dispersos por estos parajes (Sáez y Díaz 2012; Sáez y Carrero 2016), un anticipo de una realidad mucho más compleja y que deberá ser objeto en los próximos años de nuevos proyectos de investigación sistemáticos, que incluyan prospecciones mixtas terrestres y subacuáticas con carácter geoarqueológico y sobre todo sondeos estratigráficos que permitan enlazar adecuadamente ambos cauces de información (geomorfológica y arqueológica).

El objetivo esencial es revisar la atribución funcional y cronológica de uno de estos yacimientos, el situado en el Coto de la Isleta (Chiclana), en este contexto de atención renovada hacia las marismas y espacios marítimos de la zona sur de la bahía gaditana. A partir de este caso específico, se pretende también en estas páginas dar a conocer de forma integrada y reflexionar sobre un conjunto de datos arqueológicos de interés para analizar el patrón de evolución geomorfológica y el paisaje antropizado generado en la Antigüedad en el tramo meridional del caño de Sancti Petri, una de las principales arterias de comunicación y económicas de la bahía gaditana. Este conjunto de evidencias permite revisar la significación, datación y funcionalidad de un significativo grupo de yacimientos situados en ambas orillas del caño, conocidos desde diversas perspectivas anteriormente, pero apenas aprovechados en relación con el análisis de la evolución de estos espacios marismeños. El estudio pretende así revisar para la etapa romana la incidencia de estos focos de actividad en la evolución del paisaje y examinar la funcionalidad de estos espacios desde la perspectiva del modelo territorial de Gades. Cabe advertir, no obstante, desde este apartado inicial que no se trata de una tentativa de resolución de los profundos debates generados en torno a los efectos de los procesos de erosión y sedimentación que parecen haber dominado la geomorfología de esta parte de la bahía desde la Prehistoria Reciente (y cuyas líneas maestras se han definido en Arteaga y Schulz 2008; Alonso et al. 2004 y 2009), sino más bien de añadir un nuevo enfoque, basado en datos inéditos, al modelo de antropización que pudo desarrollarse en época romana en esta zona de la bahía, sobre sus amplios espacios de marismas y barras arenosas.

El caso del conocido yacimiento del Coto de la Isleta puede servir de paradigma del tipo de evidencias objeto de análisis, al haber sido su secuencia una de las pioneras objeto de escrutinio con fines geoarqueológicos en esta parte de la bahía. Los primeros análisis de campo determinaron la existencia de una importante superposición de ocupaciones entre época neolítica y moderna, que incluso ha permitido plantear interesantes hipótesis sobre la dinámica erosiva costera y las oscilaciones en el nivel del mar (Gracia et al. 1995; 2000). Se trata de un yacimiento que además ofrece unas posibilidades excepcionales de integrar lo que pudo ser un posible espacio insular de pequeñas dimensiones en la Antigüedad, en el discurso general de la formación y aprovechamiento de los espacios marismeños de la orilla continental meridional de la bahía, ofreciendo además información adicional sobre la pobremente conocida secuencia de ocupación romana del entorno del templo de Hércules Gaditanus (fig. 1). El yacimiento, ubicado en la franja sur del conocido como Coto de la Isleta, hoy rodeado de salinas en desuso (al norte y este) y de las marismas del entorno del Caño de Carboneros (al oeste y sur, conectando la isleta con el caño de Sancti Petri), garantiza, gracias a la presencia de estructuras visibles asociadas a materiales datantes, la fijación de una nueva referencia cronológica y funcional para entender las pautas de ocupación y aprovechamiento de la zona en la Antigüedad.

La metodología de investigación ha consistido en la revisión de los testimonios muebles e inmuebles sacados a la luz por la continua erosión antrópica y marina sufrida por el yacimiento. En recientes visitas al 


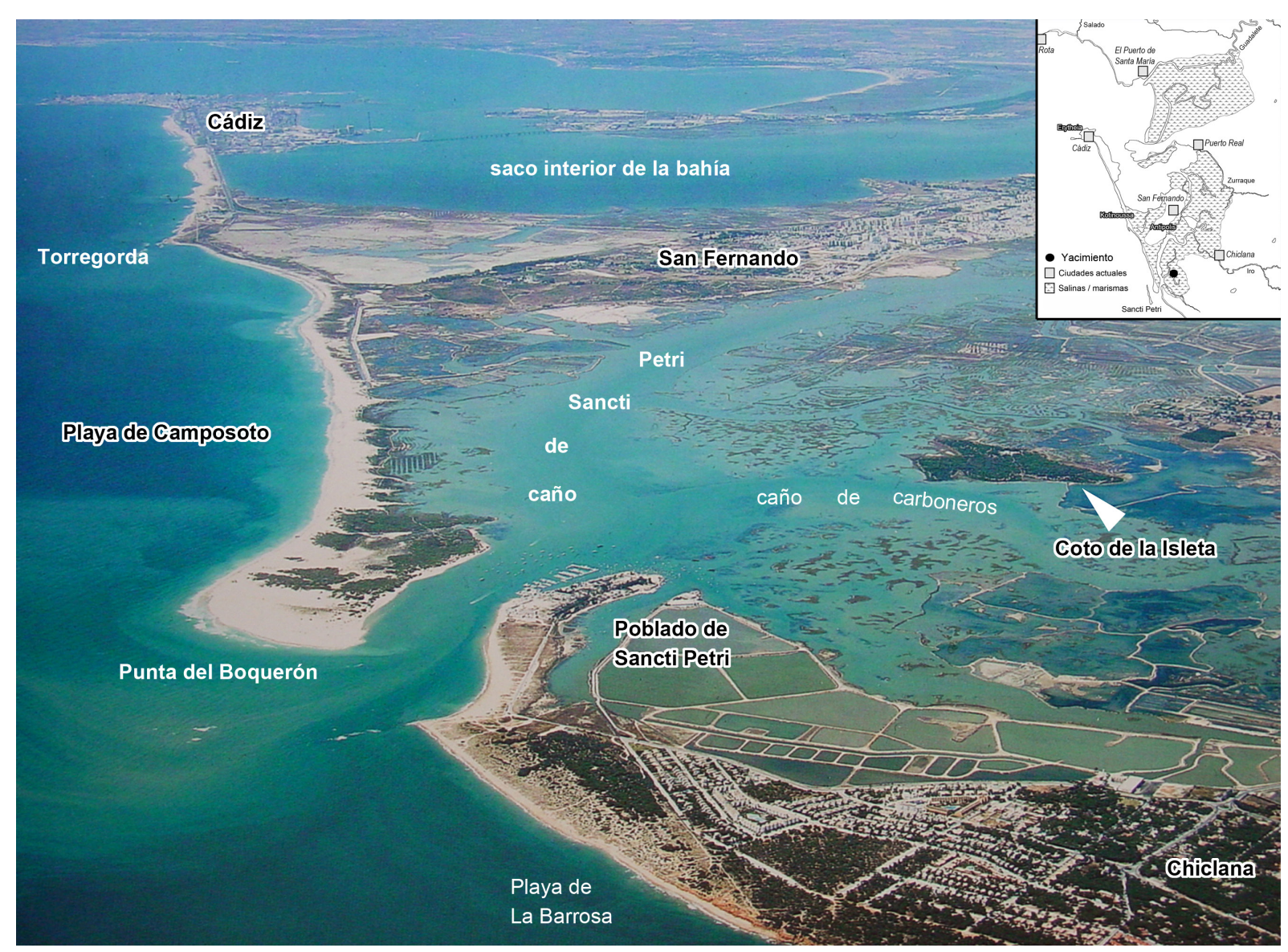

Figura 1. Fotografía a vista de pájaro de la Bahía de Cádiz tomando como eje sur-norte la barra arenosa colindante con el océano Atlántico, entre Punta del Boquerón y la ciudad de Cádiz. Se indican los principales hitos paisajísticos y arqueológicos citados en el texto, y en especial la ubicación del Coto de la Isleta de Chiclana (modificada a partir de Astilleros y Garófano 2003: 73, figura 44).

yacimiento se han relocalizado las estructuras romanas analizadas en los años 1990, evaluado in situ las evidencias muebles asociadas y realizado un levantamiento planimétrico esquemático. En conjunto, los datos recabados permiten afinar algunos detalles de la secuencia cronológica y de la estructura del asentamiento a partir de lo inicialmente propuesto por sus descubridores (Alonso et al. 1998; Gallardo et al. 2000; Gracia et al. 1995 y 2000). De este modo, como desarrollaremos en los apartados sucesivos, se puede confirmar la existencia de un establecimiento romano dotado de al menos una estructura revestida de cocciopesto (el comúnmente denominado en la bibliografía española como opus signinum), que estuvo activo como mínimo desde mediados del siglo I a.C. y a lo largo del I d.C. Otros testimonios documentados in situ, como restos de un pavimento de mosaico bícromo cercano a la estructura hidráulica, sugieren que el asentamiento pudo estar quizá vinculado a una villa u otro tipo de instalaciones de función indeterminada, acaso ligadas con la mansio itineraria Ad Herculem citada en el Itinerario de Antonino. Además, será objeto de discusión el modelo general de explotación de estos espacios atestiguado por este y otros asentamientos romanos detectados en la orilla opuesta, en la Antipolis gaditana mencionada por Estrabón (la actual San Fernando), correspondientes también con hábitats e instalaciones productivas y embarcaderos.

\subsection{Antecedentes historiográficos}

La historia de las investigaciones en el yacimiento es relativamente breve y reciente. A pesar de que la presencia de material cerámico romano en las marismas y caños del entorno del Coto de la Isleta era ya 
conocida con anterioridad (Castillo et al. 1982), hasta las campañas geoarqueológicas desarrolladas a mediados de los años 1990 en relación con el proyecto Carta Arqueológica Subacuática de la Bahía de Cádiz (impulsado por el entonces CASBC y dirigido por M. Gallardo), el yacimiento no sería localizado y se procedería a realizar una primera diagnosis científica de su entidad, función y significado (acerca del proyecto, cf. Gallardo et al. 1995 y 2000; Alonso et al. 1998). El interés de las evidencias documentadas en estas primeras prospecciones, que desafortunadamente no conllevaron la realización de sondeos, dio lugar rápidamente a una primera publicación preliminar en el año 1995 (Gracia et al. 1995), que identificó la presencia de restos neolíticos y romanos en el contexto de un análisis más general de la evolución de las marismas y la paleocosta del entorno meridional del caño de Sancti Petri, zona donde se habían concentrado las actividades subacuáticas (Gallardo et al. 1995 y 2000; Alonso et al. 1998). En este primer trabajo se definiría ya la estratigrafía del yacimiento, así como la presencia de dos piletas de salazones y un pavimento de cocciopesto, en unión de un limitado conjunto de materiales arqueológicos adscritos cronológicamente, según los autores, a los siglos II-I a.C. y al periodo altoimperial.

En trabajos posteriores del mismo equipo, también enfocados a discutir la evolución de la línea de costa en la zona sur de la bahía gaditana [así se evita usar cinco veces seguidas la preposición "de"] (Gracia et al. 2000; Alonso et al. 2009), volvemos a encontrar una interpretación similar de la secuencia, las estructuras y la cronología de la ocupación en época antigua [idem]. Un aspecto importante planteado por los descubridores del yacimiento resulta ser la identificación de diversos "niveles fósiles" que, asociados a los materiales neolíticos y romanos, sirvieron a estos autores para proponer fluctuaciones en el nivel marino, interpretando que en la fase altoimperial el mar se habría encontrado a $+0,76$ m por encima del nivel medio de 1995. Como se verá posteriormente en función de los resultados de la planimetría obtenida en nuestras visitas al yacimiento, esta hipótesis puede ser ahora discutida y considerada desde nuevas bases, fundamentadas en una identificación más concreta de las estructuras romanas y de la secuencia estratigráfica del yacimiento.

Esta primera interpretación de las estructuras y del contexto arqueológico quedaría rápidamente asentada en la historiografía posterior, dada la falta de nuevas actuaciones en el yacimiento, siendo reproducida sistemáticamente por diversos autores. En este sentido, destacan las citas en la monografía de L. Lágostena (2002: 231), apuntando al siglo I a.C. como momento de inicio de la actividad de esta cetaria; o en el trabajo dedicado por J. A. Expósito (2004: 140) a las evidencias relativas a la industria conservera de $G a$ des, apoyando este autor decididamente su interpretación como un saladero de pescado, pero retrasando el inicio de la actividad hasta época de Claudio en función de la tipología de las ánforas y la TSH. Sus propios descubridores incidirían en esta línea continuista en trabajos más recientes, centrados en el examen de la relación entre la evolución geomorfológica del litoral y la explotación de recursos salineros, alfareros y pesqueros en época romana y prerromana (Alonso y Gracia 2004; Alonso et al. 2001, 2003 y 2004). Esta continuada inclusión del yacimiento en los listados de cetariae gaditanae no dio lugar sin embargo al planteamiento de un acercamiento más profundo ni a una toma de contacto in situ con el yacimiento, en forma de nuevas actuaciones que permitiesen afinar la estratigrafía, cronología o funcionalidad de las estructuras. Así, recientemente Expósito ha reiterado una interpretación similar, aunque lamentando la falta de datos que permitan una clasificación funcional definitiva (Expósito 2011: 225; Expósito y Bernal 2016), e incluso nosotros mismos en un trabajo anterior aún seguimos la estela de esta extensa bibliografía que ligaba el yacimiento romano del Coto de la Isleta con una cetaria (Sáez y Carrero 2016).

Es posible concluir, por tanto, de este somero repaso de la investigación precedente que la tipificación del Coto de la Isleta con una "factoría de salazón" romana imperial ha quedado ya fijada como un topos frecuente en la bibliografía especializada, a pesar de que prácticamente en todos los casos se alude a la parquedad de los datos disponibles y al carácter provisional de la atribución. Dicha interpretación en cualquier caso no debe extrañar, pues se gestó en una fase de la investigación en la cual la tendencia general era la de identificar todo tipo de cubetas revestidas de cocciopesto como piletas salazoneras (como muy bien ha puesto de relieve Expósito -2004- para el caso de la zona insular de Gades). En los apartados que siguen intentaremos arrojar alguna luz adicional sobre esta cuestión, a partir del examen de nuevas evidencias y de la contextualización del yacimiento en el conjunto del poblamiento romano desarrollado en las riberas meridionales del caño y del "cabo hercúleo", una zona clave para la navegación, el comercio y la explotación de los recursos marinos ligada a Gades. 


\section{EL YACIMIENTO: UBICACIÓN, ESTRATIGRAFÍA, ESTRUCTURAS Y MATERIALES}

Como se indicó en el apartado introductorio, las actividades desarrolladas recientemente en el yacimiento se han limitado a visitas ocasionales, que han permitido únicamente documentar restos en superficie y levantar un croquis planimétrico de planta y sección de las estructuras dejadas a la vista por la erosión del reborde costero del sur de la isleta. Además de la revisión de esta zona litoral, a pesar de la densa cubierta vegetal del entorno se ha intentado delimitar el área de dispersión de las estructuras y materiales muebles de época antigua, reconociendo hacia el interior de la isleta la presencia de desniveles de posible origen antrópico (muros subyacentes), material constructivo disperso (mampuestos de piedra ostionera, tégulas y ladrillos) y de cerámicas fragmentarias. La ubicación de los restos de época romana era ya conocida tras las prospecciones del año 1994 (Gracia et al. 1995: 412, fig. 2.14), por lo que partiendo de ese dato se ha reconocido el resto de la superficie de la isleta, confirmando que las evidencias de época antigua se circunscriben únicamente a dicha localización y su entorno inmediato. La dispersión de restos constructivos y cerámicas sugiere además un perímetro reducido, de unos $80 \mathrm{~m}$ en dirección este-oeste y unos 40-50 m desde la línea costera actual hacia el interior de la isleta. En cualquier caso, es evidente que serán necesarios sondeos o prospecciones geofísicas en toda la zona, que permitan evaluar con datos más concretos la extensión del yacimiento y sus diferentes componentes cronológicos y funcionales.

En las primeras actividades de prospección efectuadas en 1994 se documentaron evidencias líticas y cerámicas de una ocupación fechada en el Neolítico, que no han sido objeto de atención en nuestras visitas al yacimiento (dado que ni en superficie ni en los cortes dejados por la erosión marina se han apreciado muestras de esta fase). En lo referido a las estructuras de época romana, se mencionaba el hallazgo de un pavimento de cocciopesto y de dos piletas de salazón de 3,4 x 1,7 $\mathrm{m}$ pertenecientes a "un pequeño complejo industrial de salazones", aunque no se publicó una planimetría o descripción detallada de estas estructuras o de su relación con los materiales usados para fechar la secuencia de ocupación (Gracia et al. 1995: 417). Puede intuirse que las piezas publicadas provendrían principalmente del entorno de las estructuras, aunque no es posible descartar que también se incluyesen fragmentos recuperados en superficie en las cercanías del pavimento y las piletas, quizá más al interior de la isleta. En todo caso, estos se corresponden con vajilla de mesa (TSH, TSG y ARSW A según sus descubridores) y ánforas eminentemente locales de la familia de las Dr. 7/11 o Beltrán IIA-B (además de un borde de T-7433), junto a importaciones de Haltern 70 del área del Guadalquivir. Actualizando la propuesta de atribución tipo-cronológica realizada entonces (Gracia et al. 1995: 417-419), tanto la vajilla como las ánforas apuntan a cronologías situadas entre el siglo I a.C. avanzado [cambiado de orden] y el tramo inicial del siglo II d.C., sin que sea razonable a tenor del contexto llevar la fecha de construcción de las estructuras al siglo II a.C.

Las visitas al yacimiento desarrolladas esporádicamente estos últimos años, que en ningún caso conllevaron la extracción de materiales o la excavación de las estructuras (de por sí "lavadas" y dañadas por la acción de las mareas y temporales), han dado lugar a la realización de una planimetría somera de la zona donde se concentran los restos visibles de estructuras (fig. 2). A partir de las ortofotografías de la zona disponibles, se ha podido ubicar la posición de la "vuelta afuera" de la cercana salina en relación con el yacimiento, posicionando la compuerta (fig. 2,1 ) y sobre todo el tramo de este muro en el que se concentra la presencia de mampostería y material cerámico procedente del cercano yacimiento romano (fig. 2, 2). Pero sobre todo se ha podido realizar un primer croquis de los restos considerados inicialmente como piletas de salazones (fig. 2, 3), obteniendo resultados limitados debido a que los aportes recientes de limos grises de marismas han colmatado la estructura. En cualquier caso, ha sido posible determinar que las dimensiones serían algo menores de las inicialmente propuestas para el lado meridional de una de las balsas (no mayor de 2,60 m), siendo evidente que existen al menos dos pilas separadas por un cordón central, dada la existencia a ambos lados de restos del revoco de cocciopesto aún conservados in situ. No se han localizado restos de otras posibles "piletas" en las inmediaciones, lo que sugiere que se trata de un conjunto aislado y no de parte de una batería más amplia de balsas, como suele ser habitual en las cetariae de la región (Expósito 2004). Por ello, nuestra interpretación de esta estructura gira en torno a su identificación con una cisterna de dos senos separados por un murete (comunicante o no) y que podría tener una cubierta plana o con una bóveda somera de ladrillo, sin que se conserven restos evidentes de ninguna de estas dos soluciones. Este tipo de estructuras de almacenamiento hidráulico es bien conocido en el ámbito de la bahía gaditana, tanto en la zona insular como continental (por 


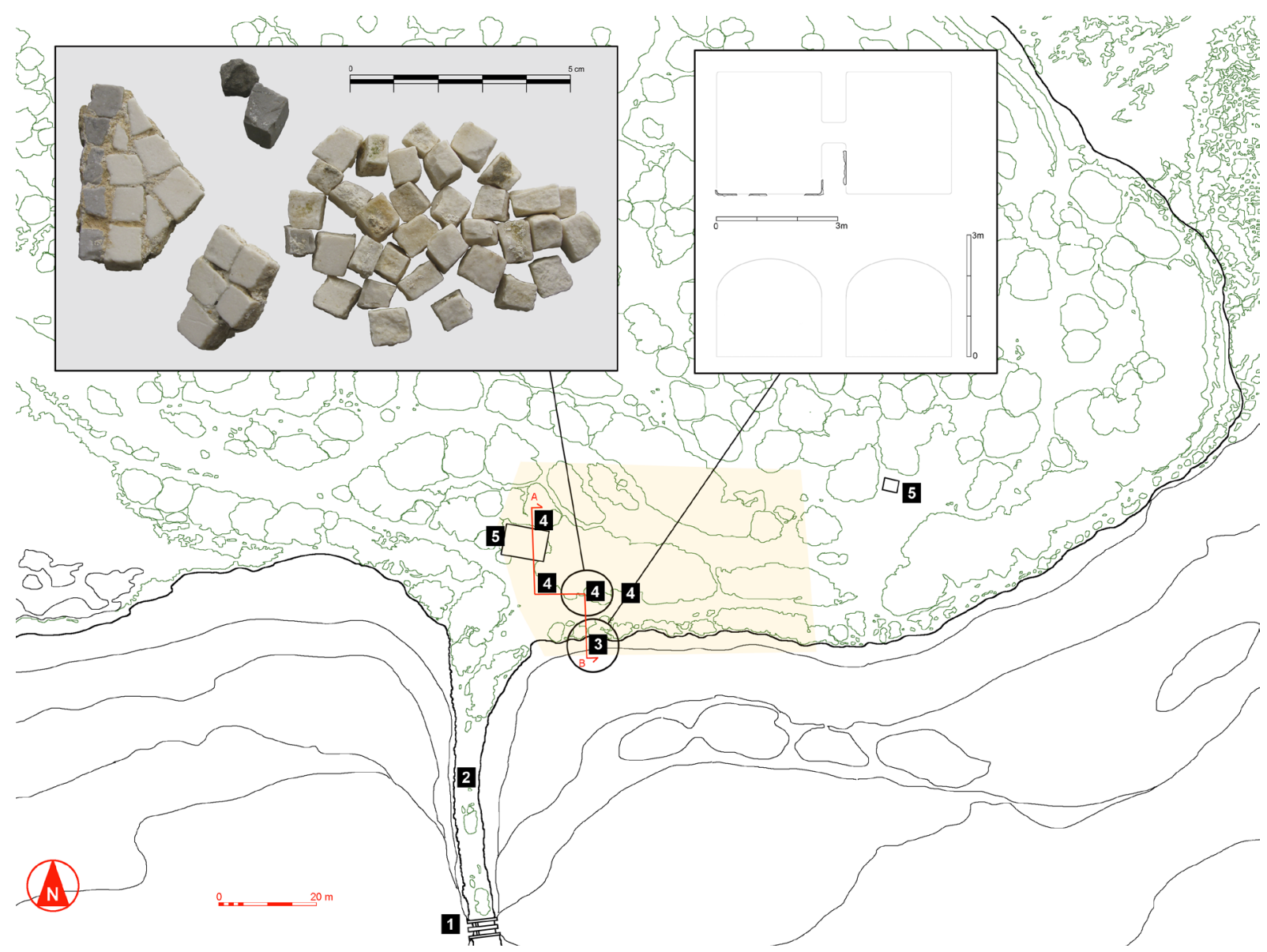

Figura 2. Esquema planimétrico de la zona sur del Coto de la Isleta, en el cual se han destacado algunos de los principales elementos descritos en el texto: compuertas (1), muro de la "vuelta afuera" (2), situación de los restos de cocciopesto (3), dispersión de cerámicas y restos edilicios romanos (4) y construcciones metálicas contemporáneas (5). En los recuadros se resaltan los restos de mosaico documentados, así como la hipótesis de reconstrucción de la posible cisterna romana a partir de las evidencias aflorantes actualmente.

ejemplo, Cobos et al. 1997), y han sido frecuentemente confundidas con balsas de uso conservero.

A pocos metros al norte de esta posible cisterna se documentan restos visiblemente deteriorados de un pavimento, quizá el identificado como "pavimento de opus signinum" por Gracia et al. (1995), que se encuentra parcialmente cubierto por los matorrales junto al camino que se ha ido configurando paralelo al reborde costero meridional de la isleta. Tras un examen detallado de los restos, se pudo concluir que la parte conservada correspondía a unos $10 \mathrm{~m}^{2}$ de la preparación de un suelo (conformando una plancha de $\mathrm{ru}$ dus/nucleus de unos 10-15 cm de grosor), vinculado a un mosaico de que contaba al menos con decoración geométrica bícroma, en gris y blanco. Fragmentos de pequeñas dimensiones de este mosaico, aún con teselas en conexión, se documentaron junto a este rudus y de forma dispersa en sus inmediaciones, sin que la inspección visual permitiese hallar teselas de otros colores o tipologías (fig. 2, 4). Pocas consideraciones adicionales cabe hacer sobre este mosaico, que se habría extendido hacia el sur y que con seguridad parece continuar también hacia el norte, probablemente en un mejor estado de conservación bajo la vegetación, puesto que lo conservado no permite elucubrar sobre sus dimensiones totales o su iconografía. En todo caso, parece oportuno recordar que este tipo de pavimentos está presente, también con motivos bicolores en gris/negro y blanco, en otros hábitats de época romana tardorrepublicana o de inicios del Alto Imperio en la propia ribera del caño de Sancti Petri (en la orilla insular, en lugares como Gallineras, Cerro de la Batería o Avenida Constitución, 


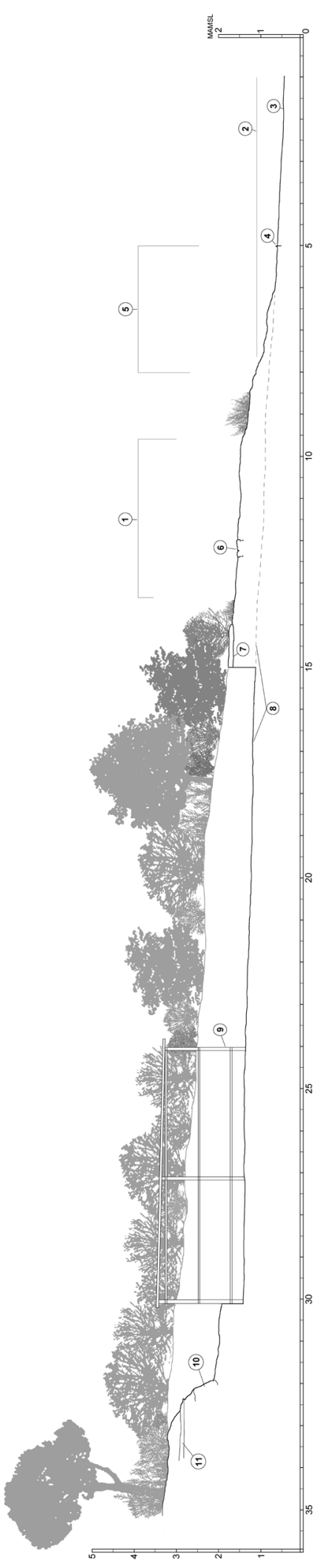

ISSN: 1133-4525 ISSN-e: 2255-3924

http://dx.doi.org/10.12795/spal.2018i27.07 m

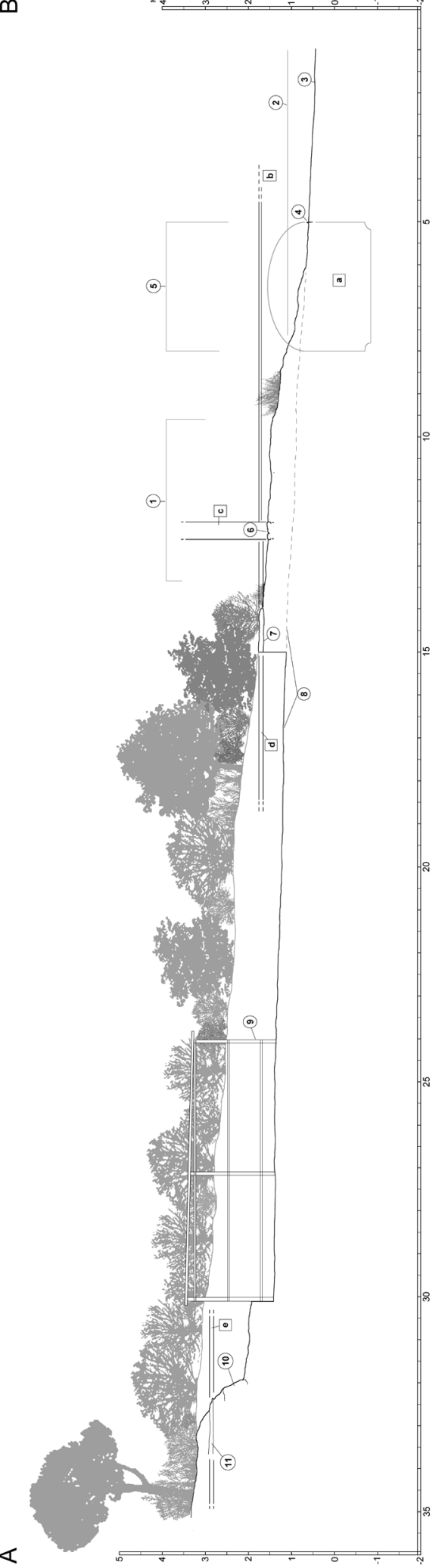

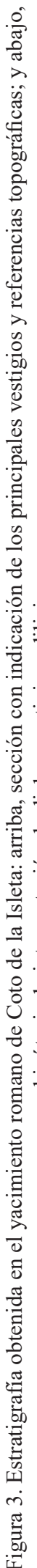




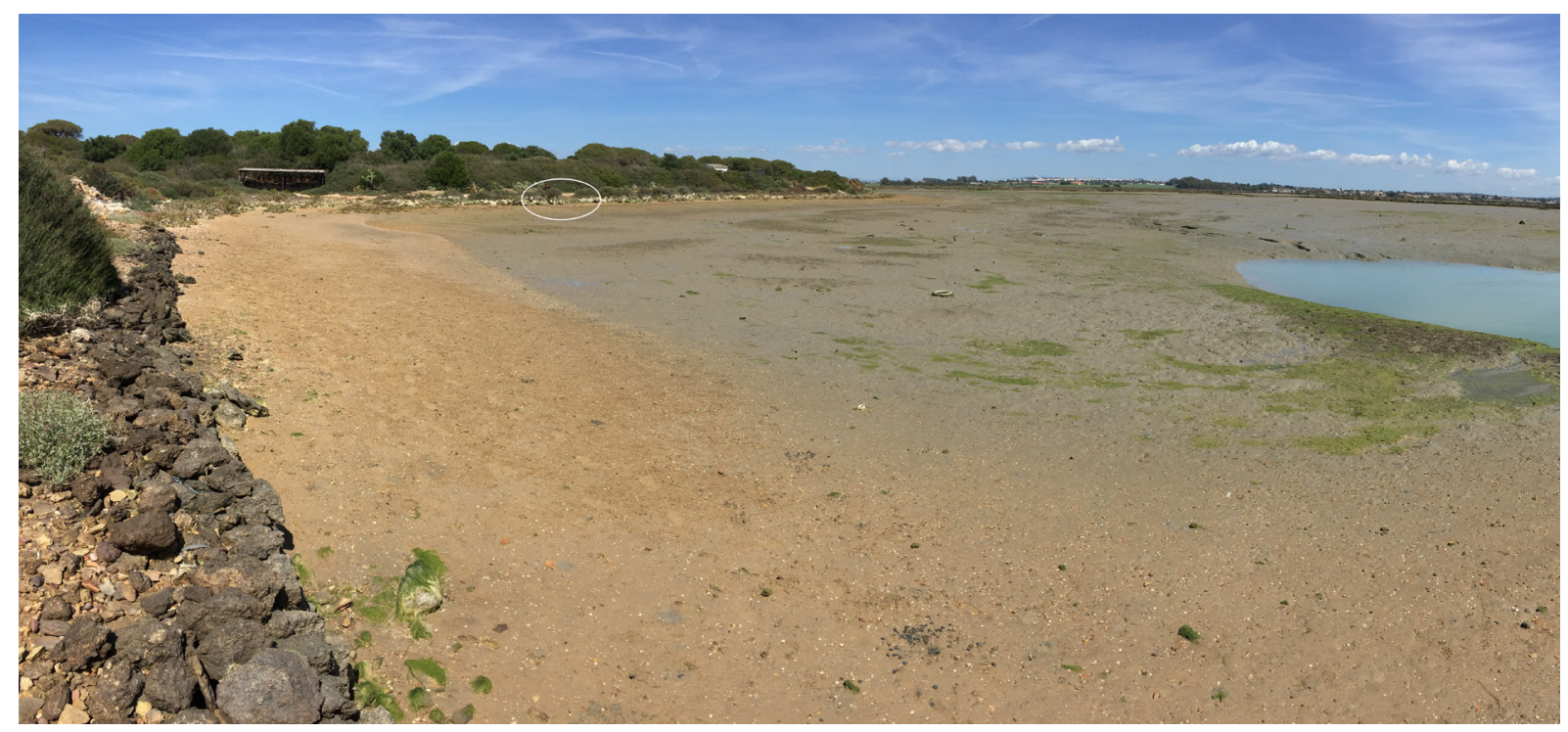

Figura 4. Vista del yacimiento desde las compuertas salineras contemporáneas, que permite apreciar el paisaje de fangos grises propio de mareas muy bajas, en las cuales la zona al interior de la "vuelta afuera" queda prácticamente desecada (el círculo indica la ubicación de las piletas y el pavimento musivario).

entre otros). Otros puntos cercanos a este pavimento musivo ofrecieron también muestras evidentes de la presencia de suelos degradados y muros subyacentes, siendo las evidencias más contundentes las documentadas en el perfil dejado tras la construcción de una caseta metálica contemporánea (fig. 2, 5, izq.). Estos datos sobre restos de estructuras, en combinación con la dispersión de materiales cerámicos (ánforas, vajillas y tégulas), han permitido proponer una extensión mínima del complejo, que abarcaría un polígono situado junto al reborde costero de no menos de 80 x 40 m (aún mayor en origen, si tenemos en cuenta la zona del yacimiento perdida debido a la erosión marina).

La lectura de la sección estratigráfica obtenida en este sector (fig. 3) ofrece incluso más elementos de juicio y perspectivas para la interpretación de las estructuras y de la incidencia de la dinámica mareal en la preservación del yacimiento (fig. 4). Como se ha descrito anteriormente, los restos aún in situ de las supuestas piletas salazoneras (fig. 3, 4) se ubican actualmente en una cota bastante inferior al máximo mareal habitual que bate el costado sur de la isleta (indicado en el corte fig. 2, 2), quedando al descubierto en momentos de bajada de la marea, cuando gran parte de la marisma que circunda los diversos brazos del caño de Carboneros queda totalmente en seco (en fig. 3, 3 se indica la tendencia descendente de estos fangos). La orientación de los fragmentos de cocciopesto sugiere un desarrollo soterrado de esta posible cisterna doble hacia el norte (figs. 3, 5), en dirección al camino actualmente casi desprovisto de vegetación, también parcialmente afectado por la erosión marina (fig. 3, 1). En este tramo ubicado entre la estructura hidráulica y el camino, son varias las zonas horadadas por el agua en las cuales se agolpan fragmentos cerámicos, restos malacológicos diversos, fragmentos de tégulas y ladrillos e incluso trozos de cocciopesto (quizá correspondientes a partes de la propia cisterna o de suelos destruidos que cubriesen originalmente la estructura; fig. 5). El interior de la posible cisterna (fig. 3, a) queda totalmente oculto tanto en esta parte como en la afectada por la marisma, debido a la deposición de limos grises que enmascaran los estratos originales de colmatación (fig. 6).

La combinación de la acción mareal y del uso antrópico continuado del camino (fig. 3,1 ) ha dejado también al descubierto parte de la cimentación de un muro, dispuesto casi en dirección este-oeste y paralelo a la posible cisterna, del cual son visibles varios mampuestos heterométricos en conexión (fig. 3, 6 y fig. 7). La reconstrucción en alzado de este muro (fig. 3, c) y de la posible cubierta de la cisterna, así como la proyección hacia el sur del pavimento que cubriría a aquella (fig. 3 , b), permite intuir la existencia de dos espacios diferenciados: uno al sur, de dimensiones y tipo de suelo indeterminados, que habría sido prácticamente borrado por la erosión marina y bajo el cual se habría situado la cisterna; y uno al norte, en el cual se encontraría el pavimento de mosaico, pero del cual tampoco es posible definir su 
Figura 5. Tramo de la costa situado junto al mosaico y los restos de cocciopesto de la posible cisterna, el cual ilustra el efecto erosivo constante de las mareas y temporales.

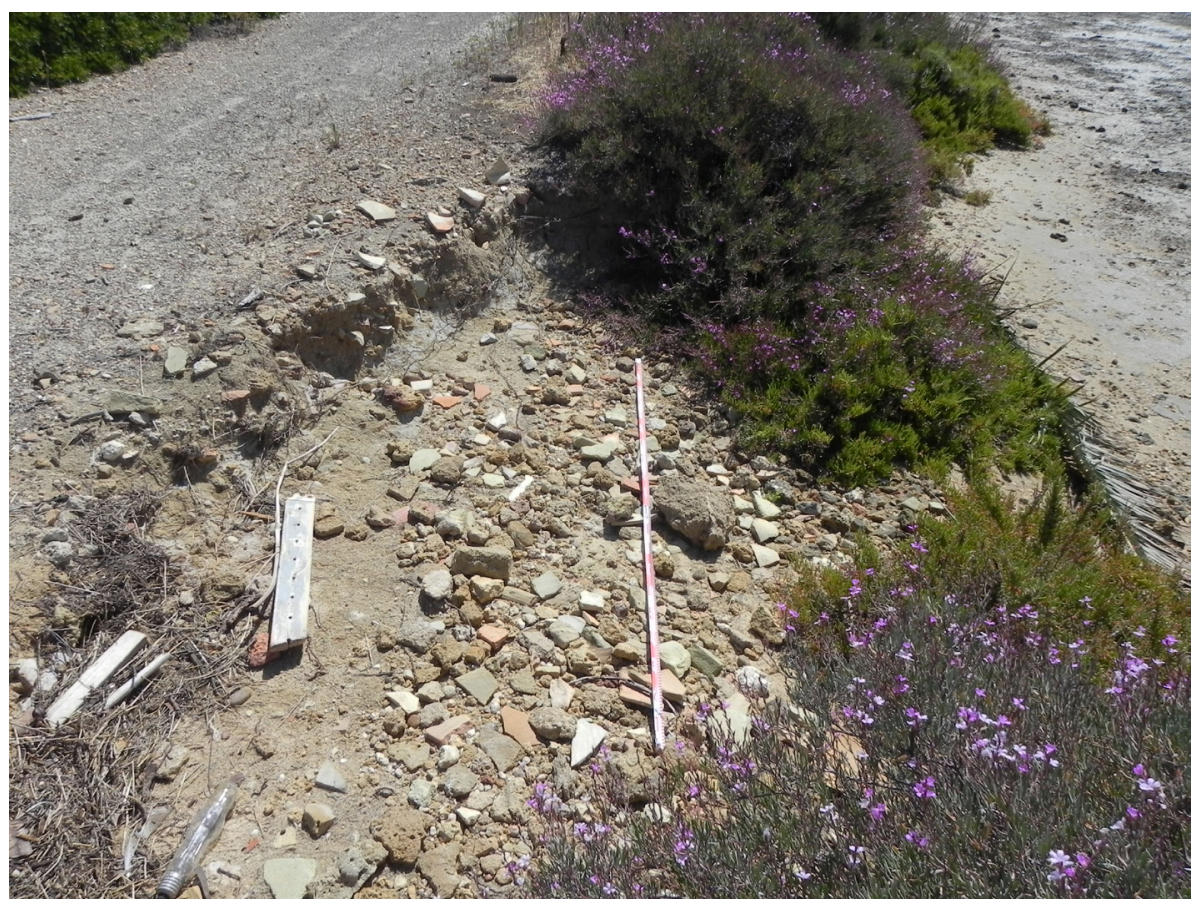

morfología o extensión (fig. 8). Los únicos restos visibles actualmente de este espacio septentrional corresponden a la porción del rudus del mosaico ya citada (fig. 3, 7), estando buena parte de esta preparación similar al cocciopesto (a base fundamentalmente de cal y arena) disgregada, y dispersas las teselas blancas y grisáceas entre la maleza y en el propio camino. Únicamente puede asegurarse la proyección de este suelo hacia el norte, aunque no es posible determinar la entidad del mosaico ni su estado de preservación más al interior de la isleta (fig. 3, d).

El corte en el terreno derivado de la construcción de la caseta metálica situada al noroeste de las principales estructuras no permite distinguir en su sección nortesur la presencia de estructuras, que sin embargo sí son claramente visibles en el corte este-oeste situado en su parte trasera (fig. 9). Este rebaje del terreno significó

Figura 6. Restos de cocciopesto in situ cubiertos parcialmente por fangos grises de marisma y por la vegetación. Las líneas blancas de trazo discontinuo indican el trazado del perímetro de las cubetas totalmente oculto actualmente.

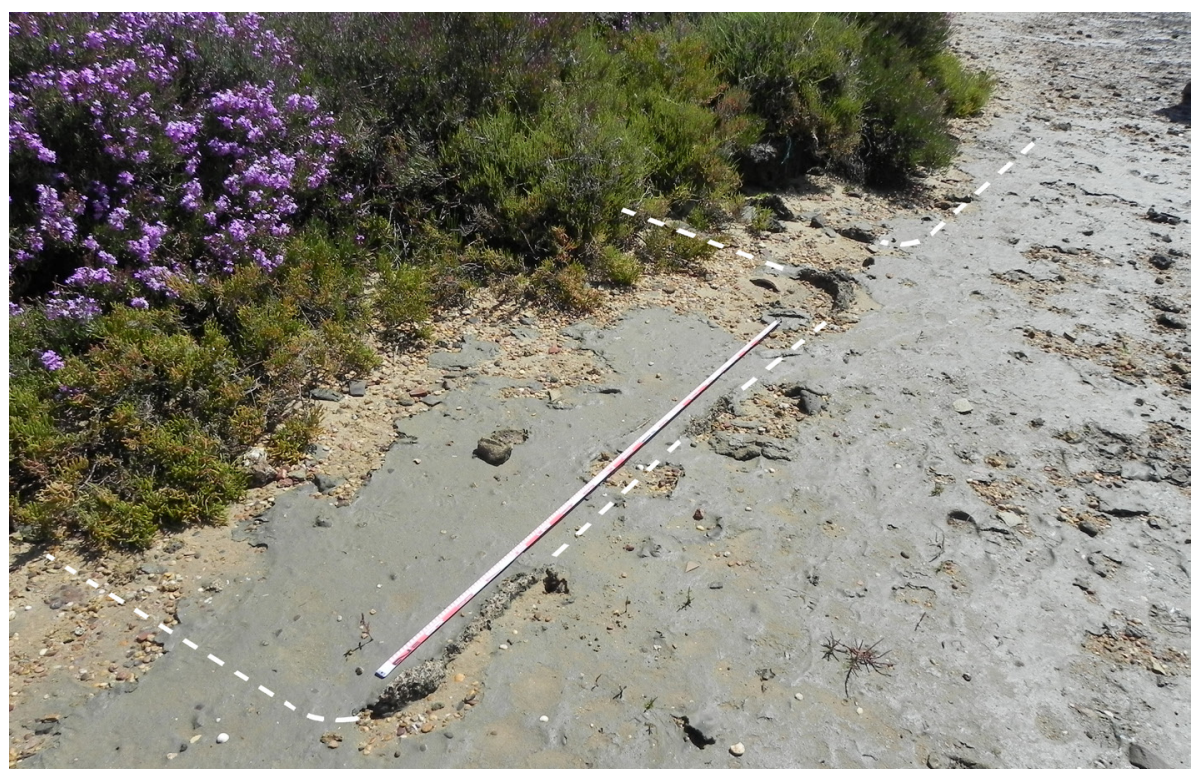




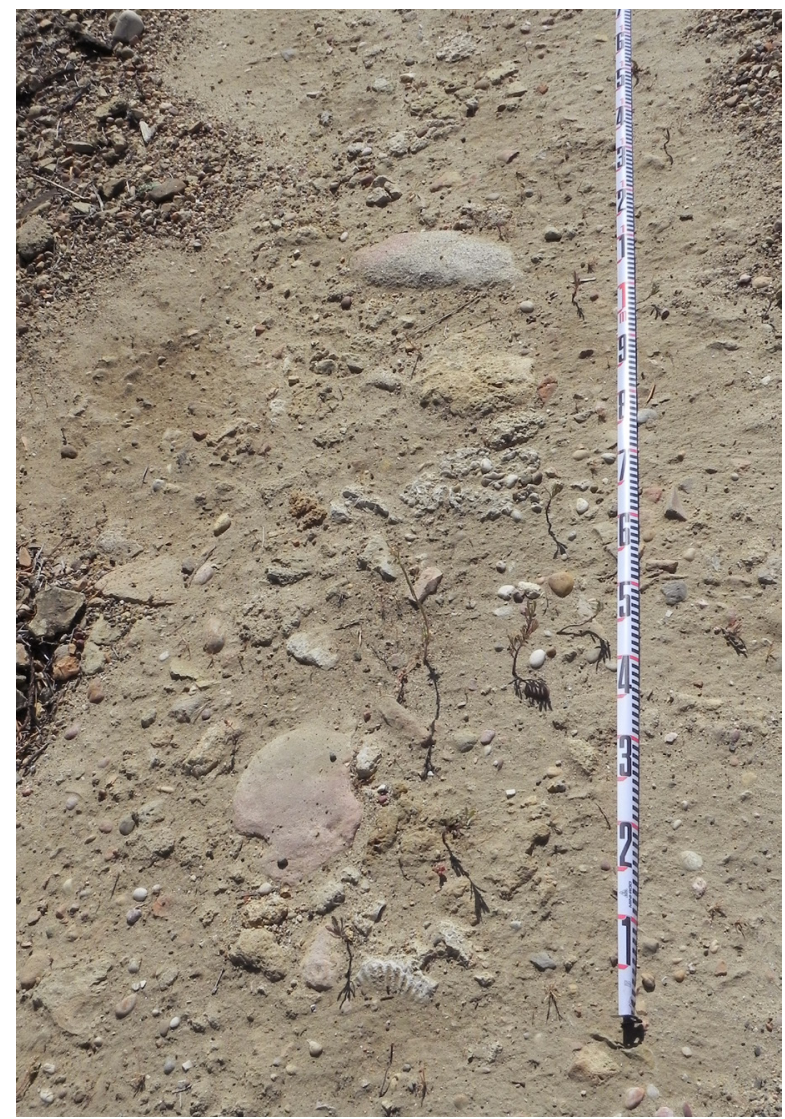

Figura 7. Mampuestos de diverso tamaño y composición petrográfica dispuestos en aparente conexión, documentados en las cercanías del pavimento de mosaico, definiendo un posible muro paralelo a la cisterna.

una remoción integral de toda la estratigrafía afectada, desde el techo hasta más allá de los sustratos de arcillas rojas que constituyen la base. Aunque la zona se encuentra muy degradada por el uso antrópico y llena de matorral, ha sido posible distinguir la presencia de un posible muro de tosca factura (fig. 3,10$)$ y de una interfacie de suelo (fig. 3,11 ) situada a una cota más elevada, cuya proyección hacia el sur evidencia que se trata de un pavimento ubicado en una pequeña terraza más alta que el suelo de mosaico (fig. 3, e). Ante la falta de una excavación de estos restos, no cabe sino conjeturar las dos opciones más plausibles: por una parte, que se trata de la muestra más evidente de la existencia de dos fases de ocupación diferenciadas del lugar, ambas de época romana, que quizá no tengan conexión entre sí; o bien que ambas fases sí estuviesen conectadas, y en un momento dado la edificación sufrió una reforma que determinó el aterrazamiento del espacio, dejando a un nivel más alto las estancias ubicadas en esta parte más interna de la isleta. Es evidente que esta ocupación más alta se proyecta hacia el norte, no siendo posible sin realizar catas determinar la entidad de este suelo, sus dimensiones o su posible conexión con muros. El posible muro ubicado a una cota inferior, con una fábrica compuesta por material constructivo fragmentario reutilizado y mampuestos de pequeño porte, parece que podría encajar con la zona baja de un tabique vinculado a la misma fase del pavimento musivario, extremo que solo podrá ser verificado mediante el desarrollo de sondeos estratigráficos que conecten ambas zonas.

La mayor parte de los materiales muebles examinados se documentaron asociados a los frentes erosivos dejados por la acción mareal junto a la posible cisterna y al camino ubicado junto a este reborde costero, donde cada anualidad nuevos fragmentos cerámicos, materiales constructivos, malacofauna y fragmentos de cocciopesto son dejados al descubierto por la repetitiva actuación de las mareas y los temporales. Aunque una buena parte de los elementos diagnósticos corresponde a restos de ánforas, cabe destacar la abundancia de fragmentos de vajillas barnizadas de mesa, cerámicas comunes diversas y piezas de cocina, caracterizando un asentamiento polifuncional cuyo registro no parece casar con lo esperable en una instalación netamente industrial.

Entre las ánforas, los elementos más antiguos reconocidos corresponden a un borde de T-7433 (fig. 10, 13) y otro de Ovoide Gaditana (fig. 10, 1), ambos con pastas propias de la bahía, cuyos perfiles sugieren fechas tardías ya dentro del siglo I a.C., quizá hacia 50-40 a.C. (García Vargas et al. 2011; Sáez et al. 2012). El resto de las producciones cuyas pastas también parecen apuntar a un origen en talleres gaditanos corresponde a diversas variantes de la familia de las Dr. 7/11, tanto bordes (fig. 10, 2-6, 8-12 y 16-17) como asas (fig. 10, 7), así como un par de pequeños fragmentos de borde que podrían corresponder a formas tempranas del tipo Beltrán II o modelos en transición desde las Dr. 7/11 tardías (fig. 10, 14-15). En todo caso, el conjunto señala con claridad el predominio de materiales fechables entre la fase augustea y la dinastía flavia (García Vargas 1998 y 2010), siendo incluso probable que los modelos del tipo Beltrán II correspondan a producciones del tramo final del siglo I d.C. (García Vargas 1998). Todos ellos se relacionan esencialmente con el transporte de salazones y salsas de pescado, aunque en casos como las T-7433 cabe no desechar el transporte de caldos locales.

Respecto a las ánforas importadas, en conjunto remiten al mismo horizonte cronológico ya descrito, proviniendo en su mayor parte de talleres del área del Guadalquivir (García Vargas et al. 2011). Debido a la 
Figura 8. Detalle de los restos de rudus aún conservados in situ o parcialmente removidos. En esta zona se documentaron los restos de teselas, así como

cerámicas romanas y tégulas fragmentadas.

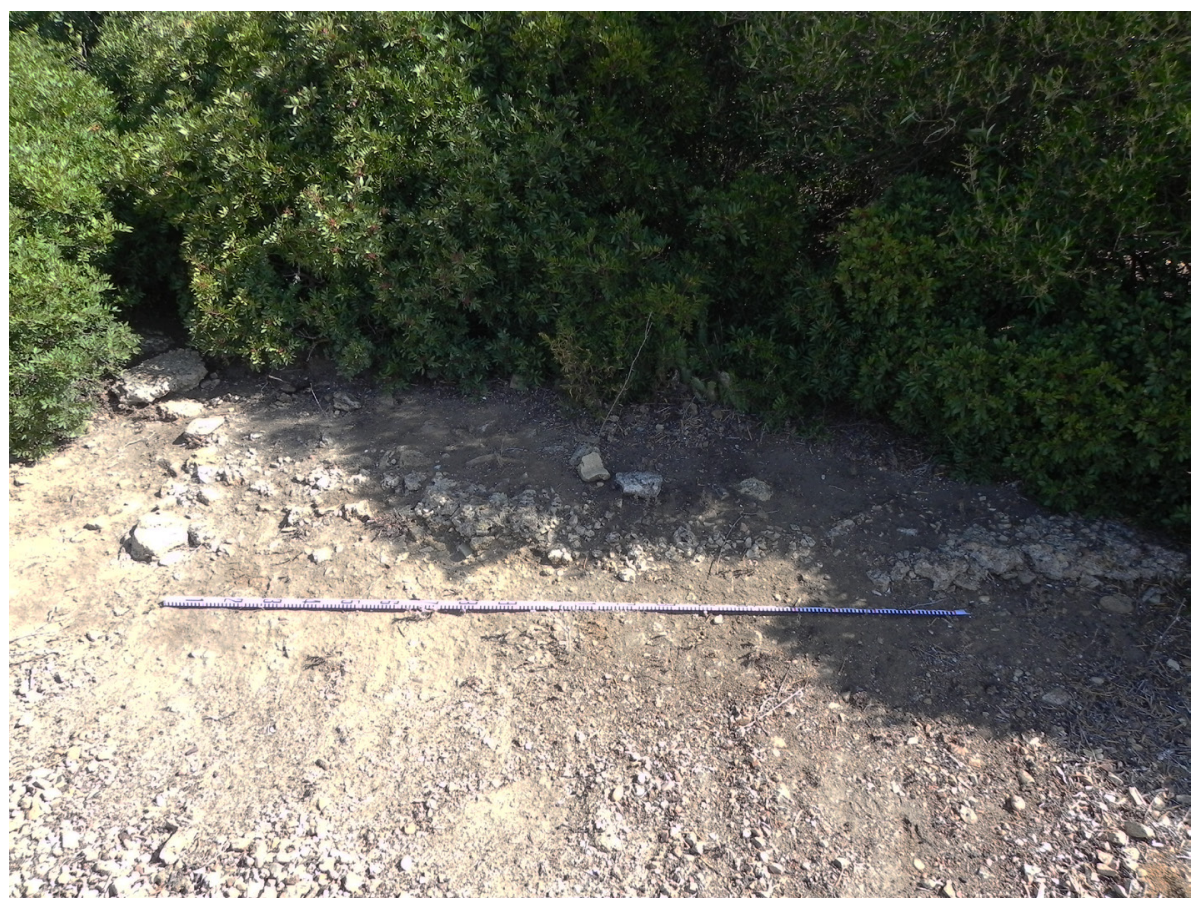

gran fragmentación del material resulta complejo precisar tipos concretos, pero parecen ser predominantes las ánforas olearias encuadradas quizá en la forma Ovoide 6 (fig. 11, 1-2), Oberaden 83 (fig. 11, 3) o incluso Haltern 71 o Dressel 20 inicial (fig. 11, 10). Otros elementos como pivotes -todos ellos con grafitos precocción- podrían corresponder a individuos de estas mismas tipologías (fig. 11, 5-6), así como algún asa (fig. 11, 8-9), sin que podamos excluir que alguna de estas últimas o uno de los pivotes puedan corresponder a ánforas del tipo Ovoide 4 o Haltern 70 inicial (fig. 11, 4). A este mismo grupo cabe asociar un fragmento de cuerpo recortado hasta conferirle una forma circular, usado probablemente como opérculo (fig. 11,7). Un último fragmento de Haltern 70 remite a prototipos tardíos de la serie, datados en época flavia (Berni 2011), caracterizados por bordes estilizados y engrosados en la parte interna (fig. 11, 13). En suma, una nutrida representación de ánforas

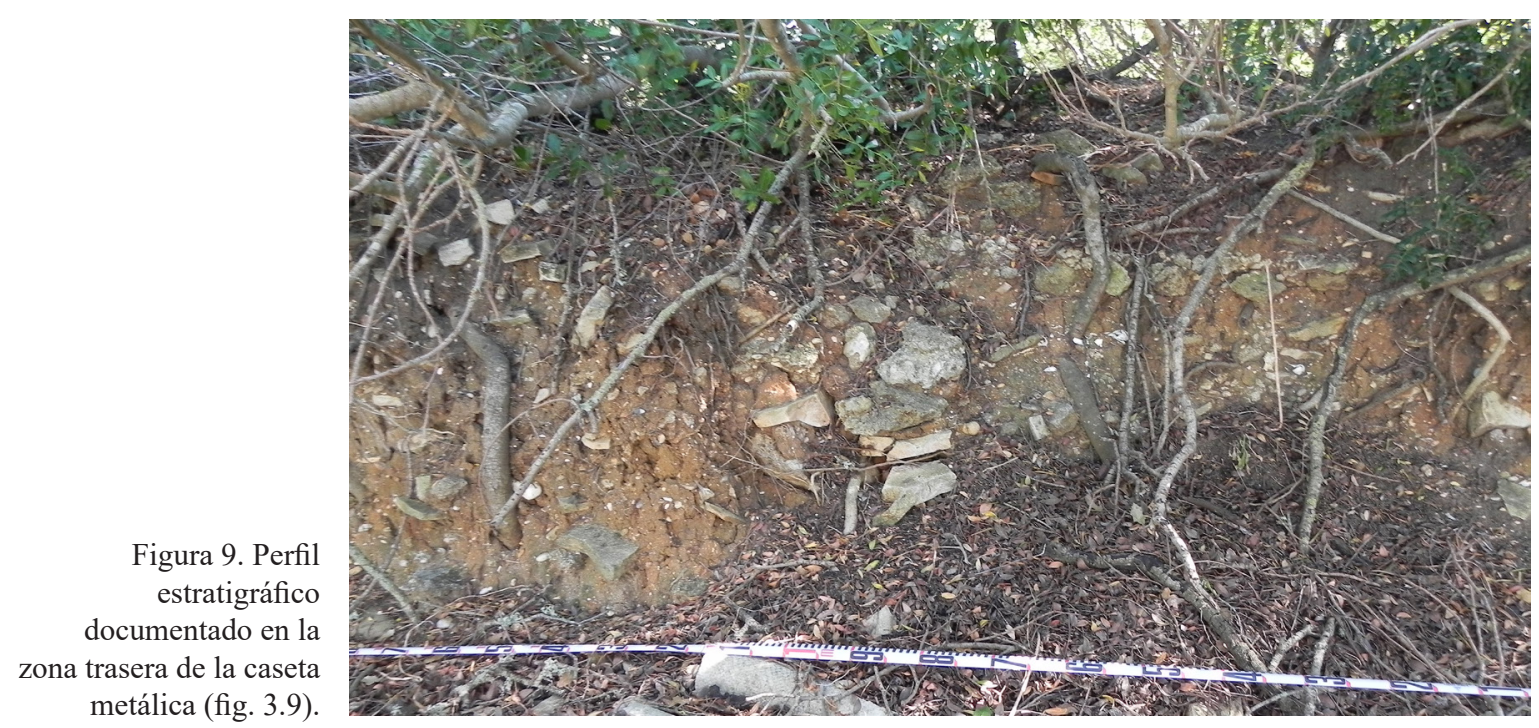



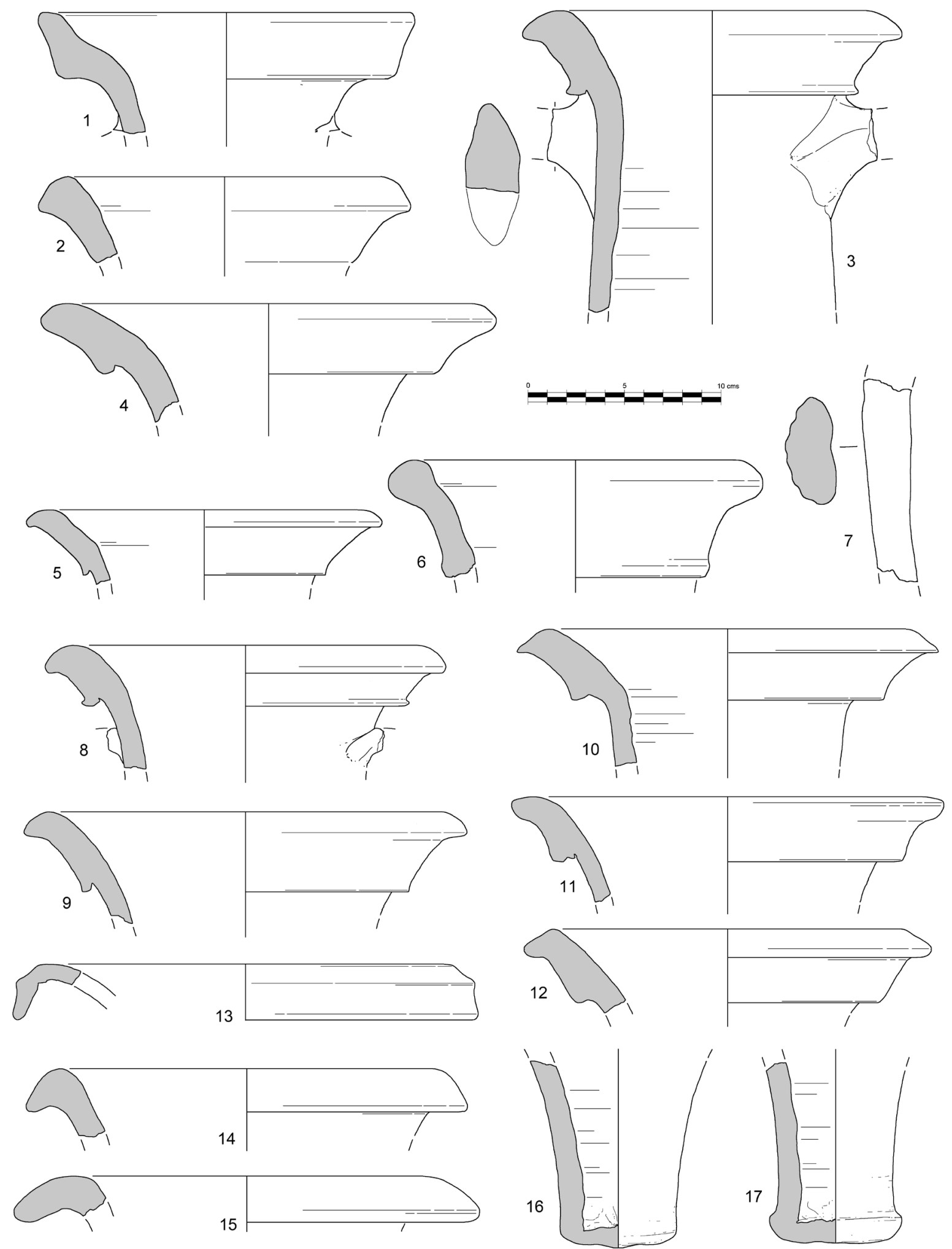

Figura 10. Ánforas producidas en la bahía de Cádiz documentadas en Coto de la Isleta. 

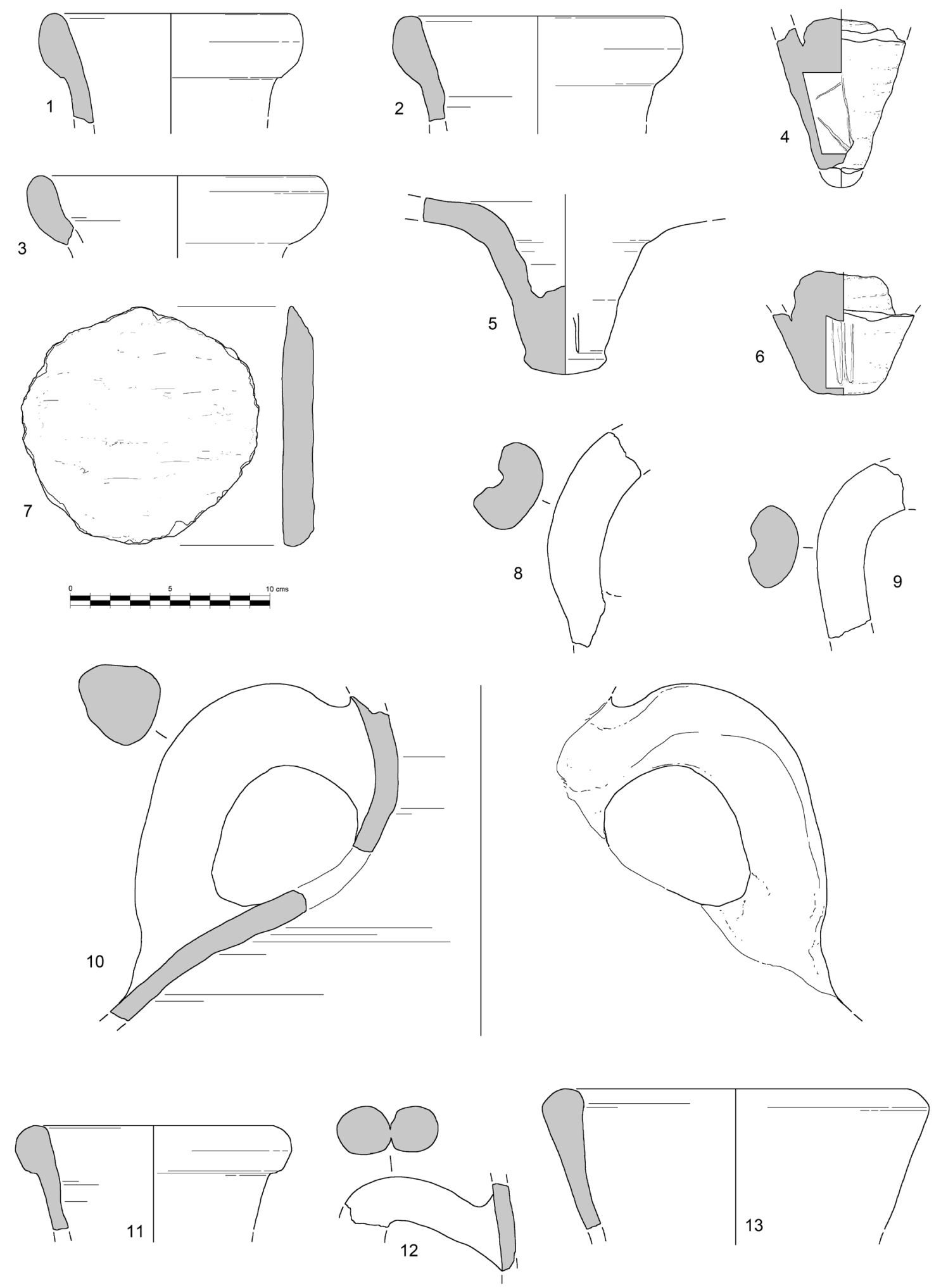

Figura 11. Importaciones anfóricas de origen diverso de Coto de la Isleta. 


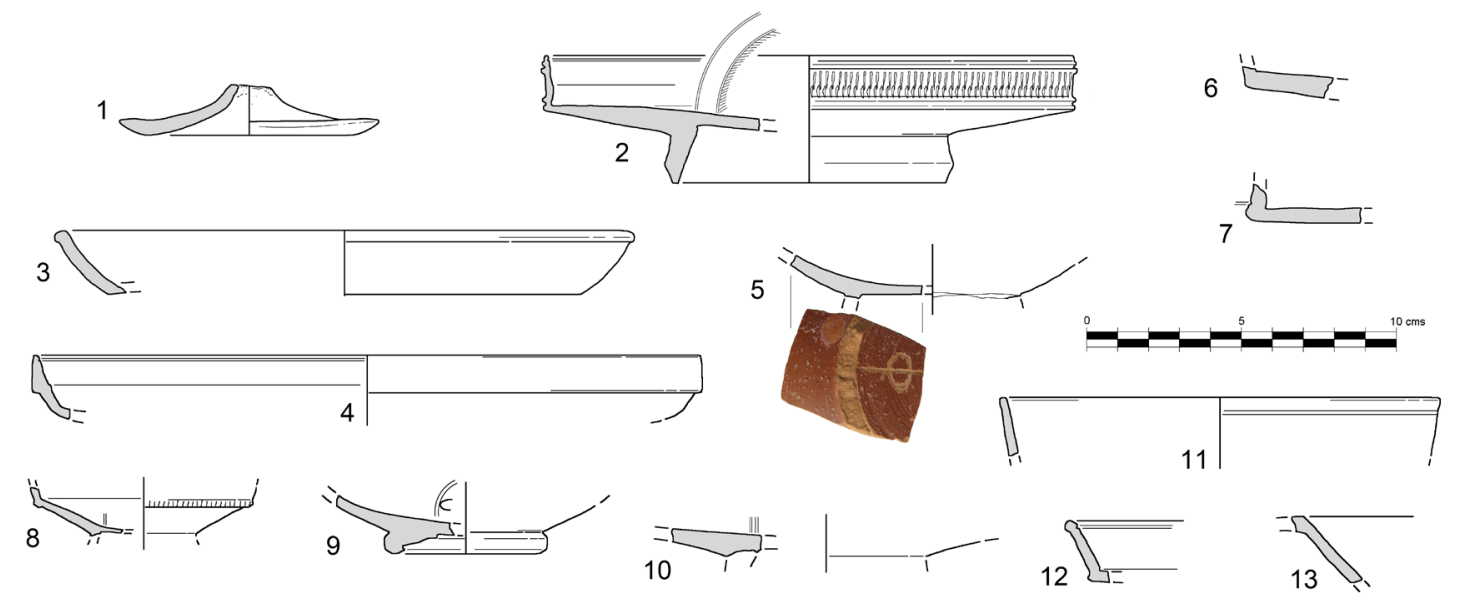

$1 4 \longdiv { 2 }$
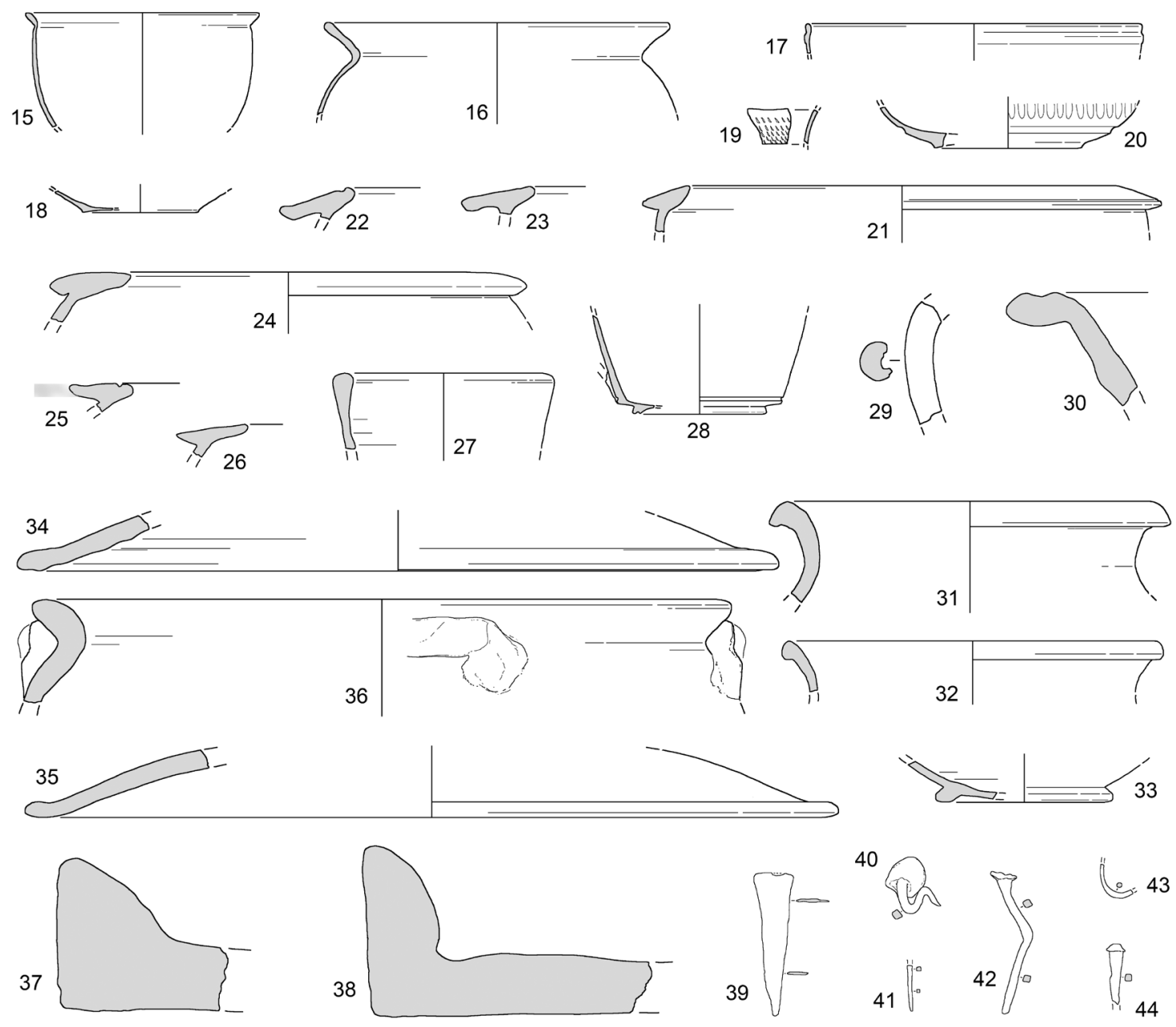

Figura 12. Opérculo anfórico (1), vajilla barnizada (2-14), cerámica de paredes finas (15-20, 28-29), cerámicas comunes y de cocina (21-27, 30-33), tégulas (37-38) y objetos metálicos (39-44) de Coto de la Isleta. 
olearias y vinarias (respectivamente) del área del Guadalquivir que no resulta extraña en la zona, con evidencias de la recepción de productos de esta región tanto en la cercana Antipolis (Bernal et al. 2006) como en el propio puerto insular de Gades (Sáez et al. 2016). A ellas cabe sumar fragmentos de asa y borde correspondientes a dos individuos de ánforas vinarias del tipo Dr. $2 / 4$, cuya pasta sugiere un posible origen tarraconense (fig. 11, 11-12).

El resto de los materiales cerámicos asociados a la estructura revestida de cocciopesto y a los depósitos erosionados en torno a los restos del rudus del mosaico corresponde a producciones no anfóricas, que incluyen sin embargo diversos fragmentos de opérculos sencillos que por sus características de pasta probablemente podamos asociar a las ánforas de la serie Dr. 7/11 (fig. $12,1)$. Destacan los fragmentos de vajilla de mesa documentados, correspondientes tanto a terra sigillata itálica (fig. 12, 2, 8 y 10-13) como gálica (¿fig. 12, 3?) e hispánica (fig. 12, 5-7 y 9, con sello ilegible). Entre estos últimos, una de las bases presenta un grafito realizado post-cocción que parece representar la letra griega phi, quizá esgrafiada en la parte exterior de la base de la pieza como marca de propiedad (fig. 12, 5 y fig. 13). Estos platos y copas pudieron haberse combinado en el asentamiento con el uso de vasos y cuencos de paredes finas, entre los cuales encontramos una posible Mayet III (fig. 12, 16), una Mayet IX (fig. 12, 15), una Mayet XII o XIV (fig. 12, 28) y diversos fragmentos, mayoritariamente con "pastas béticas", de vasos anchos no muy profundos decorados en ocasiones con ruedecilla al exterior (fig. 12, 17-20 y 29).

El repertorio de cerámicas comunes sin tratamiento superficial incluye formas muy populares entre la producción de los talleres gaditanos, como un borde de un "vasito perforado" (fig. 12, 27), una forma frecuentemente documentada junto a piletas en el territorio gaditano y quizá vinculadas a una función como filtro o embudo de sustancias oleosas o salsas de pescado (Bernal y Sáez 2006). El resto de formas identificables corresponde a lebrillos profundos (fig. 12, 30) o tinajas de tamaño medio (fig. 12, 31-32), más algunas jarras de pequeño porte (fig. 12, 33). Son abundantes también las ollas con bordes planos proyectados hacia el exterior (fig. 12, 21-26), alguna de ellas con ennegrecidos que demuestran su uso para la cocción de alimentos, siendo una serie cuya producción está ampliamente atestiguada en alfares altoimperiales de la bahía (Girón 2010; Sáez y Díaz 2014). Cabe citar la presencia de otras formas vinculadas a la cocina, como tapaderas de amplio diámetro con pastas itálicas (fig. 12, 34-35)

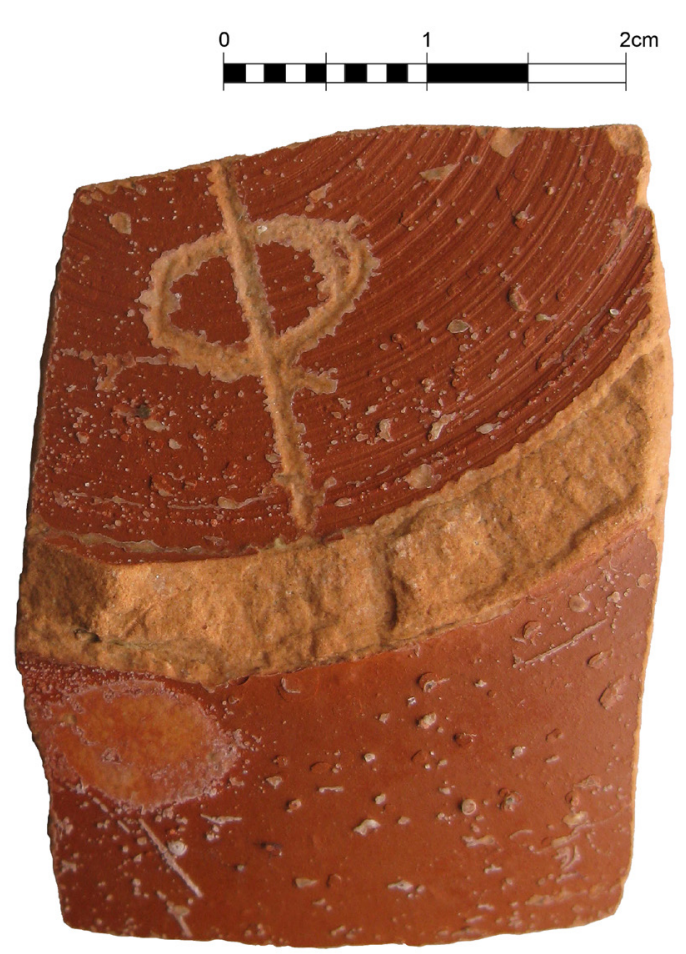

Figura 13. Imagen de detalle del grafito post-cocción grabado en la parte inferior de un cuenco de TSH, posiblemente representando la letra griega phi.

o una olla de grandes dimensiones dotada de asas horizontales (fig. 12, 36).

Además de los materiales cerámicos junto al pavimento musivo y a la ubicación de las piletas, se documentaron sin asociación directa a ninguna de las estructuras algunos elementos metálicos, todos ellos en bronce, que pueden identificarse mayoritariamente como clavos de vástago cuadrado de variado tamaño (fig. 12, 40-42 y 44). Otro fragmento de mayores dimensiones corresponde a una plaquita muy fina de forma triangular y funcionalidad indeterminada (fig. $12,39)$, mientras que un pequeño fragmento de sección esferoidal y forma redondeada podría quizá corresponder a un anzuelo, del que no se conservan ni la punta ni el vástago completo (fig. 12, 43).

En la franja situada al norte de las estructuras dejadas al descubierto por la erosión, la gran densidad de la cubierta vegetal, con abundante matorral de gran tamaño, ha impedido recuperar una cantidad de material reseñable y ha limitado las posibilidades de establecer asociaciones entre ellos. Como en la zona costera, se documentaron abundantes fragmentos de tégulas de diversa tipología y pastas aparentemente de la propia 

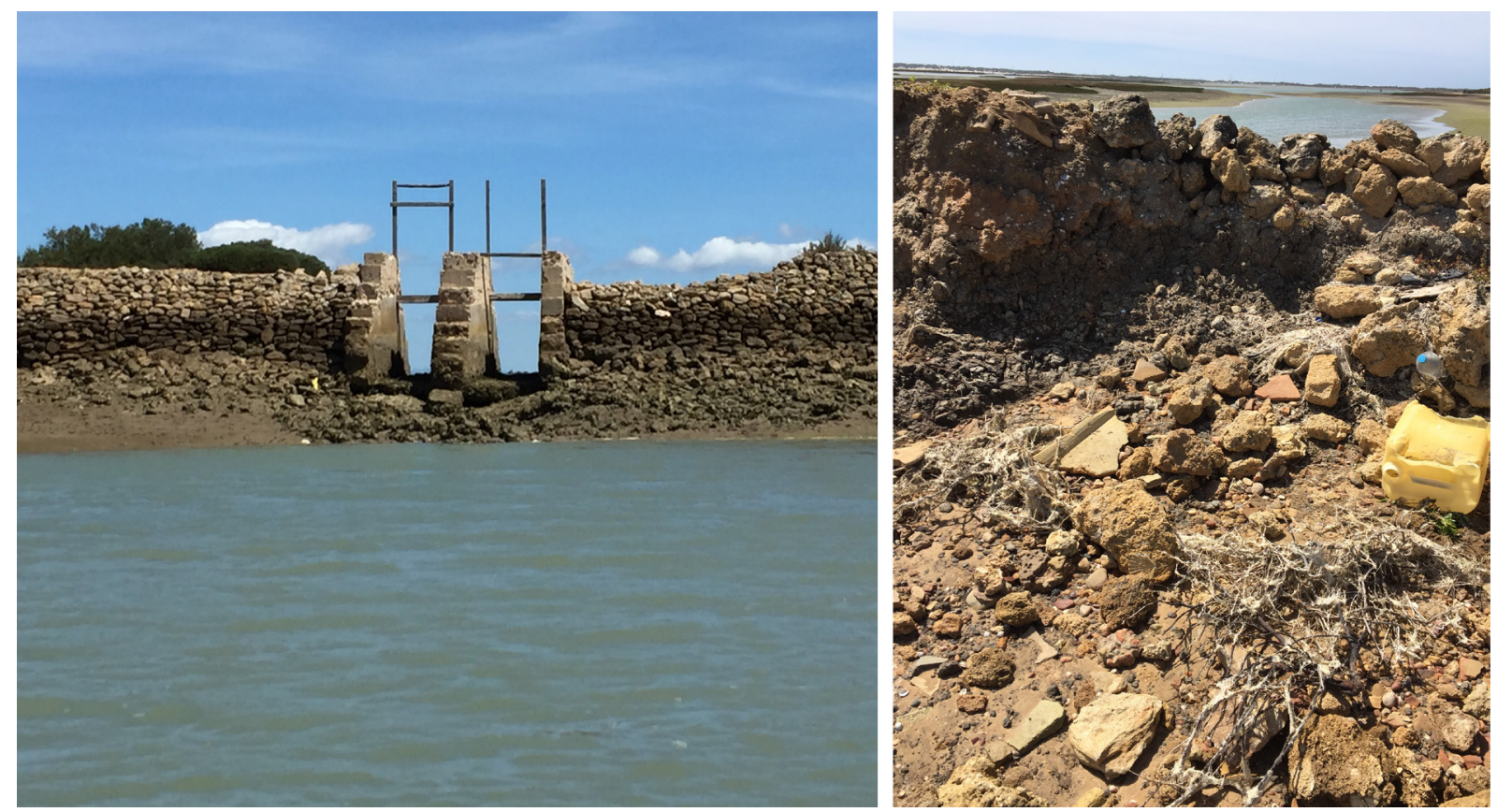

Figura 14. Vista de las compuertas y la fachada del muro de la "vuelta afuera" desde uno de los caños menores de Carboneros próxima a la isleta (izquierda) y detalle del proceso de degradación de la cara interna del mismo muro (derecha). En esta imagen es perceptible la presencia de abundante material cerámico y constructivo romano en el relleno del muro.

bahía (fig. 12, 37-38), galbos de cerámicas comunes y ánforas, y un pequeño fragmento de vajilla de mesa africana ASRW D. Se trata de un borde que, a pesar de la erosión superficial, puede identificarse como parte de un plato del tipo Hayes 87A fabricado con pasta D2 (fig. 12, 14), una importación que se viene fechando en la segunda mitad del siglo V d.C. (Atlante 1981: 9394) o incluso en los inicios del VI (Bonifay 2004: 173177). Este hallazgo aislado, recuperado en la superficie de la parte del yacimiento situada al interior de la isleta, permite así constatar la existencia de una fase de ocupación tardoantigua del asentamiento, aunque por el momento no sea posible determinar si se asocia con estructura alguna (como por ejemplo el pavimento más superficial y los niveles de amortización asociados, detectados en el corte estratigráfico situado detrás de la caseta metálica) y si supone una continuidad del asentamiento tardorrepublicano, o por el contrario corresponde a un horizonte desconectado del anterior.

La inspección visual superficial del entorno ha permitido constatar, gracias a la degradación estructural del cercano muro de la "vuelta afuera", cómo los trabajos de reconstrucción de este muro y de la cercana compuerta doble conllevaron la destrucción parcial del yacimiento. El muro está constituido por un relleno de tierra proveniente de la isleta, seguramente extraída de la zona donde se ubica la caseta metálica, en la cual son abundantes los materiales constructivos y cerámicas de época romana (fig. 14). Este relleno se forró en ambas caras con mampuestos heterométricos de ostionera, parte de los cuales es posible también que provengan de las estructuras romanas desmontadas en las cercanías. En la actualidad parte de este muro, la situada entre la compuerta y la isleta, se encuentra parcialmente derrumbada hacia el este, dejando al descubierto este expolio y aportando materiales de forma desordenada a la marisma inmediata. En cualquier caso, los numerosos (y en ocasiones voluminosos) fragmentos de tégulas, ladrillos o ánforas remiten al mismo horizonte cronológico, caracterizado por los materiales asociados a las estructuras conservadas in situ.

Los datos que manejamos ahora, por tanto, sobre el yacimiento aportan una lectura estratigráfica significativamente distinta de la ofrecida hace apenas dos décadas, dejando entrever la existencia de más de una fase en la ocupación del lugar durante la época romana y tardoantigua. Asimismo, permiten cuestionar su atribución sin más debate al catálogo de cetariae gaditanae, sugiriendo, al menos para la parte del mismo evaluable en superficie, que este pudo corresponderse con la porción habitacional de un asentamiento quizá del tipo villa. No puede, no obstante, descartarse que el lugar 
fuese ocupado por una factoría conservera en algún momento de su secuencia de actividad, o que se relacionase íntimamente con faenas pesqueras o salineras, algo que parece del todo lógico y esperable a tenor de su localización y de la dinámica económica general de la urbe gaditana. Sin embargo, consideramos que los restos identificados como piletas bien podrían corresponder a una cisterna destinada al almacenamiento hídrico más que a balsas para salar pescado, dadas su dimensiones, tipología y relación espacial directa con los restos del pavimento de mosaico. Ambas hipótesis quedan en cualquier caso sujetas a la realización futura de sondeos y excavaciones en extensión en el yacimiento, las cuales permitan dar lugar a un diagnóstico más preciso de la tipología de las estructuras y sus relaciones estratigráficas.

\section{EL COTO DE LA ISLETA EN CONTEXTO: NUEVAS Y VIEJAS EVIDENCIAS}

El examen de la evolución histórica de las marismas y la línea de costa en este tramo meridional del actual caño de Sancti Petri, y sobre todo en el frente oceánico vinculado a la islita homónima y a la Playa de Camposoto, han sido un objetivo preferente de la investigación geoarqueológica desde hace varias décadas. El principal caballo de batalla ha sido el de la caracterización de los cambios en la fisonomía del litoral y la determinación de la incidencia de los procesos de erosión marina, midiéndose desde diversas aproximaciones metodológicas la regresión del frente costero constituido por la barra arenosa de Camposoto y el islote de Sancti Petri. Todas las propuestas coinciden en señalar la desaparición de buena parte de la isla-barrera original que unía ambas en la Antigüedad. En este análisis de la geomorfología del tramo costero sur de la bahía, la existencia de diversos indicadores arqueológicos ha sido decisiva para el planteamiento de las dispares hipótesis y modelos de interpretación, tanto para época fenicia/romana (Alonso et al. 2009; Sáez y Díaz 2012) como para momentos mucho más recientes (un ejemplo en Fernández-Montblanc et al. 2016). Sin embargo, y partiendo de la premisa de que ya en la Antigüedad al oriente de este frente insular existían amplios espacios de marismas explotados con fines salineros (Alonso et al. 2001 y 2003), no se ha puesto un esfuerzo equivalente en la caracterización de la evolución de las llanuras de limos, en constante crecimiento y transformación debido a la acción marina y la aportación de sedimentos por parte del Guadalete y el Iro.
En este contexto historiográfico cabe insertar los datos procedentes del Coto de la Isleta y la discusión sobre su funcionalidad y cronología de ocupación. Debemos además señalar, en este inicio del apartado, que existe un limitado número de referencias estratificadas y adecuadamente contextualizadas obtenidas en el curso de actividades arqueológicas puntuales en la zona, las cuales se enmarcan en esfuerzos puntuales derivados de la Arqueología Preventiva y no en el seno de proyectos sistemáticos de investigación (aspecto que grosso modo es extensible al ámbito estrictamente subacuático, en el cual desde las iniciativas de los años 1990 no se ha vuelto a llevar a cabo una prospección sistemática de estos espacios marino-costeros, dominando el seguimiento de diversas tareas de dragado del caño principal con fines portuarios).

Por nuestra parte, este marco general dibujado por las investigaciones desarrolladas en las dos últimas décadas para la Antigüedad (esencialmente, Arteaga y Schulz 2008; Alonso et al. 2009) se ha intentado complementar y matizar con un análisis más microespacial de determinadas evidencias ubicadas tanto en las áreas arenosas como en las marismeñas, y también con la aportación de excavaciones en yacimientos ubicados en la zona de contacto entre los limos y la isla de $\mathrm{An}$ tipolis (identificada con la actual San Fernando). Este trabajo de recopilación ha combinado el estudio de evidencias rescatadas en diversos momentos y depositadas en almacenes de museos, con la realización de visitas al reborde marítimo de ambas márgenes del caño y al entorno, revisando localizaciones previamente conocidas por bibliografía o situando puntos hasta entonces inéditos en el mapa. Esta labor de reconocimiento por vía pedestre o marítima ha permitido identificar algunas evidencias adicionales vinculadas a yacimientos de época antigua, fenicio-púnica y romana, tanto en localizaciones ya conocidas como sobre todo en las no conocidas previamente (una síntesis en Sáez y Díaz 2012; también cf. Díaz et al. 2012; Sáez y Carrero e.p.).

En cualquier caso, no es el objetivo de estas páginas discutir la evolución geomorfológica de este sector de la bahía gaditana o de la línea de costa, al menos no más allá de lo que afecta estrictamente al discurso vinculado a esbozar los hitos del paisaje de época romana que permitan contextualizar el yacimiento del Coto de la Isleta, siendo esto último el fin esencial de este apartado. Incidiremos por tanto ahora en una síntesis sobre los hallazgos de época romana registrados en la zona desde hace décadas, intentando ofrecer una interpretación global de su significado y evolución que permita profundizar en el papel que el asentamiento de la isleta 
pudo desempeñar en el escenario general, utilizando como base geomorfológica las conclusiones generales ya planteadas en las obras de referencias citadas anteriormente.

De este modo, asumimos como punto de partida general que se trataría de un Caño de Sancti Petri más abierto al océano que el actual y con una anchura y calado también mayores, que permitirían el paso a embarcaciones de todo porte e incluso a las migraciones estacionales del atún (como aún sucedía en el siglo XVI, según autores locales como Horozco). La costa oceánica cercana habría estado constituida por una barra arenosa más potente en anchura y quizá más elevada sobre la cota actual del nivel del mar, con un retroceso que tal vez pueda superar los $250 \mathrm{~m}$ en este tramo meridional insular (Gracia et al. 1999 y 2000; Bethencourt et al. 2011; Fernández-Montblanc et al. 2016). Por su parte, las marismas situadas junto a la barra de Camposoto en esta época habrían estado ya desarrolladas y posiblemente explotadas como salinas (desde al menos la Avenida Constitución hasta la Punta del Boquerón), así como parte de las marismas ubicadas junto a la actual costa de Chiclana (desde la desembocadura del Iro hasta la playa de La Barrosa). Para el caso concreto del Coto de la Isleta, resulta por el momento imposible asegurar si su insularidad se mantuvo durante toda la Antigüedad o si, por el contrario, ya en época romana o tardoantigua la isleta se habría visto soldada al continente mediante marismas consolidadas, explotables con fines salineros (Alonso et al. 2001, 2003 y 2009), o incluso si la construcción de algún camino o embarcadero artificial pudo acelerar el proceso. Se trata sin duda de una de las cuestiones más perentorias a resolver en torno a la investigación del yacimiento, lo que deberá implicar el desarrollo de un amplio proyecto geoarqueológico específico.

Desde los inicios de la investigación existe unanimidad en situar en el extremo meridional de la isla gaditana el emplazamiento del santuario dedicado a Melqart / Hércules Gaditano, que a partir de la fundación de la propia urbe en época fenicia constituía uno de sus principales hitos cultuales, económicos y marítimos (Quintero 1906; García y Bellido 1963). Son conocidos los hallazgos, en los bajos que circundan el islote de Sancti Petri y la desembocadura del caño, de elementos tanto de cronología fenicia (Blanco 1985; Sáez et al. 2005) como romana (García y Bellido 1963), que certifican la ubicación del santuario en este sector, si bien no se poseen indicios demasiado precisos de su localización concreta, sus características arquitectónicas o sus dimensiones (algo ya destacado en Corzo 1992 y en la generalidad de la bibliografía previa). En relación con la búsqueda de este santuario, el caso del islote de Sancti Petri ha sido considerado en trabajos previos con amplitud (Sáez y Díaz 2012), por lo que no insistiremos en lo evidente al señalar que este santuario habría sido el eje articulador del paisaje de todo el sector, tanto en lo referido a los ejes viarios y la navegación como en la explotación económica del entorno.

Tampoco insistiremos en que se encuentra necesitado de un proyecto específico que aborde la complejísima problemática de su evolución geomorfológica e histórica, aunque sí merece la pena apuntar que evidentemente el templo ejerció un papel fundamental en la gestión del territorio circundante, íntimamente ligado a la circulación marítima y a la explotación de los recursos pesqueros (algo que probablemente era así desde la etapa prerromana, como ya se propuso en Sáez Romero 2009). La presencia de cetariae a lo largo del frente oceánico de la barra de Camposoto parece que tuvo en época romana imperial su momento de máximo esplendor, existiendo indicios de este tipo de instalaciones desde Torregorda y los arrecifes del entorno de La Albufera (donde parecen conservarse restos de piletas aún in situ), hasta el tramo central y meridional de la playa de Camposoto, con al menos dos localizaciones de gran entidad donde también se ha documentado ampliamente la presencia de material constructivo (sillería, mampuestos, ladrillos, tégulas), fragmentos de cocciopesto, ánforas e incluso un desecho de cocción que sugiere la presencia de alfares (Díaz et al. 2012; Sáez y Díaz 2012; Sáez y Carrero e.p.). Se trataría por tanto de un área con una importante componente pesquero-conservera y, en general, industrial, que sin duda se complementaría con la cercanía a salinas y embarcaderos ubicados en las áreas mareales circundantes. El propio templo podría haber participado lucrativamente en estas actividades, las cuales discurrían junto al tramo de vía costera que unía el santuario con la ciudad (Corzo 1992; Vallespín 2004; Sáez et al. 2004).

Siguiendo la interpretación tradicional ofrecida para los restos de Coto de la Isleta, el yacimiento se habría integrado en esta tupida red de factorías y áreas de producción, aunque a la vista de los nuevos datos presentados en estas páginas quizá no como una cetaria, sino como una instalación de tipo villa o alguna clase de edificación vinculada a este escenario económico e itinerario. La presencia de salinas y embarcaderos diseminados por todo el sector, desde el reborde meridional de la Antipolis hasta la desembocadura del Iro o del paleocaño de Sancti Petri, parece confirmada por yacimientos como Los Cargaderos (Bernal et al. 


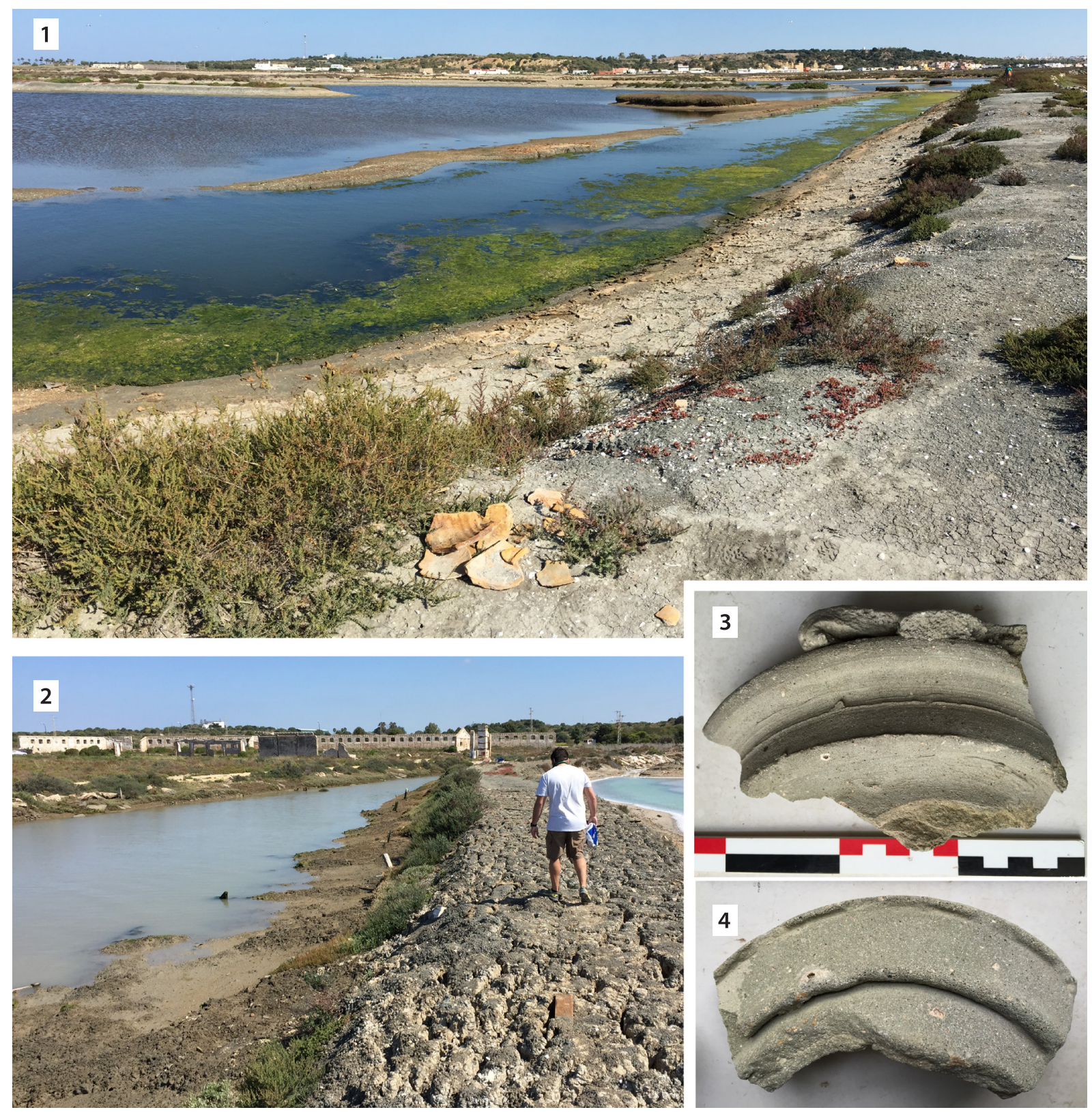

Figura 15. 1. Evidencias documentadas en la orilla opuesta del caño de Sancti Petri: arriba, "vuelta afuera" de la Salina El Estanquillo, no lejos del muelle actual de Gallineras, en cuya superficie se puede apreciar la abundante presencia de material romano fragmentado; 2. "Vuelta afuera" de la misma salina recién regenerada, colindante con el yacimiento de La Almadraba, con presencia también de abundante material cerámico antiguo; 3 y 4. Desechos de cocción de ánforas romanas documentados en esta segunda localización.

2006, datado en época flavia), así como por la abundante presencia de materiales cerámicos y de construcción en el entorno de la salina de El Estanquillo y todo el tramo marismeño que discurre hacia el actual puerto de Gallineras. En las "vueltas afuera" de dicha salina (una zona de marismas consolidada en la Prehistoria
Reciente; cf. Arteaga y Schulz 2008) resulta frecuente encontrar restos de ánforas y vajillas que se datan entre la época púnica y la tardoantigüedad, siendo los más numerosos los fragmentos de tégulas y ladrillos y de ánforas romanas altoimperiales (fig. 15). En sus cercanías, algo más al sur, en los caños de la Almadraba 
(junto al sistema de caños denominado "Las Dos Hermanas") existen evidencias similares, que además de incluir restos dispersos de cerámica también denotan la presencia de instalaciones alfareras tardorrepublicanas/altoimperiales dedicadas a la producción masiva de ánforas (Díaz et al. 2004). Otros yacimientos ubicados en la franja marismeña que se extiende entre las arenas de Camposoto, el Río Arillo y el acuartelamiento militar han sido también objeto de prospección en la última década, ofreciendo en conjunto un panorama que dibuja una intensa ocupación de todo el frente litoral insular meridional (Sáez y Díaz 2012).

Posiblemente pueda ser el yacimiento de Gallineras - Cerro de los Mártires, con evidencias de ocupación desde época púnica, el que más intensivamente se haya investigado y aporte una fotografía más clara de cómo pudo ser el modelo de asentamiento rural que se habría desarrollado en el Coto de la Isleta. Además de una probable explotación salinera de los espacios marismeños consolidados ya desde la fase prerromana frente al yacimiento, la excavación parcial de su zona baja (Gallineras) ha revelado testimonios evidentes de su adecuación para tareas portuarias y relacionadas con posibles vivaria (testimoniados por conjuntos de piletas de $5 \times 2 \mathrm{~m}$ conectadas entre sí por tubos de plomo). En esta zona baja además se han documentado indicios de amplios espacios pavimentados con cocciopesto, y de un hueco de pozo que podría indicar la presencia de una cisterna. Además son notables los vestigios relativos a la producción alfarera, y sobre todo de ánforas y material constructivo, desarrollada esencialmente durante la etapa tardorrepublicana y de inicios del Imperio. En las proximidades de este núcleo industrial se documentaron también diversos espacios dispuestos en torno a un patio, pavimentados con mosaicos, estando conservado en condiciones relativamente buenas uno de tipo geométrico en blanco y negro. Otras evidencias cerámicas dispersas, así como algunos enterramientos de inhumación, sugieren una continuidad en el uso de este emplazamiento hasta momentos avanzados de la Antigüedad Tardía (una síntesis actualizada sobre el yacimiento en Díaz y Sáez 2016).

Esta dinámica de uso de los espacios marismeños y de la orilla inmediata de la antigua Antipolis, corazón del territorium insular de Gades, tiene continuidad aparentemente bajo los mismos parámetros hacia el norte, prácticamente hasta enlazar con el núcleo de poblamiento localizado en el área del actual Puerto Real. Sin abandonar el marco de atención preferente de este trabajo, cabe citar ejemplos ribereños del caño como la Calle Asteroides (Bernal et al. 2007), el Cerro de la
Batería (Sáez y Montero 2007) o la Avenida Constitución (Bernal et al. 2005) en los cuales se documentan, sobre la base de instalaciones alfareras púnicas, asentamientos de tipo villático también dotados de potentes áreas productivas anejas, similares al caso más ampliamente investigado de Gallineras. En la parte opuesta, en la ribera meridional del caño de Sancti Petri, las investigaciones sobre el patrón de ocupación del territorio en época antigua han sido menos sistemáticas que en la orilla norte, si bien cabe pensar también en la presencia de asentamientos tipo villa dispersos por la campiña costera de la actual Chiclana. En concreto, debemos destacar la presencia de alfarerías en puntos como Loma del Puerco (en la costa oceánica) o en las cercanías del curso del Iro, particularmente en el entorno de la urbe moderna (Lagóstena y Bernal 2004), destacando las evidencias de una posible villa o aglomeración rural en el entorno del Cerro del Castillo y Huerta Alta (Bueno y Cerpa 2010). Cabe pensar en todo caso en el uso preferente de la red de caños como nexos de conexión rápida entre ambas orillas y entre los propios asentamientos, pudiendo presumirse para la fase tardorrepublicana y de inicios del Imperio una fluida relación entre las cetariae de Camposoto, los asentamientos de Almadraba-Gallineras y la instalación asentada en el Coto de la Isleta.

Por último, es necesario resaltar también la existencia de sugerentes datos procedentes de contextos subacuáticos conocidos en este mismo entorno. Los restos de naufragios de época antigua documentados en este sector son verdaderamente exiguos, lo que se viene atribuyendo en buena medida al retroceso de la línea costera, que estaría apuntando a que los pecios se encuentran más alejados de la costa actual respecto de las zonas objeto de prospecciones en el frente de la playa de Camposoto (Bethencourt et al. 2011), o en las inmediaciones del islote o la desembocadura del caño de Sancti Petri (normalmente ligadas a dragados puntuales realizados para mantener la navegabilidad con seguridad de esta arteria). Un primer indicio en este sentido fue documentado en el curso de los trabajos dirigidos por O. Vallespín (1985 y 1986) a poniente del actual islote de Sancti Petri, donde fueron documentados los restos de un pecio de época romana que entre su cargamento portaba lingotes (tortas) de cobre de 40 y $60 \mathrm{~kg}$, así como lingotes de plomo en forma de barras con un peso medio de $65 \mathrm{~kg}$, tipologías ambas que remiten a una actividad fechable en el siglo I d.C.

Posteriormente, prospecciones llevadas a cabo entre los años 1993 y 1995 en la propia desembocadura del caño (la denominada "zona B") permitieron 
documentar, a una profundidad media de unos $10 \mathrm{~m}$, abundantes restos tanto de época altoimperial como bajoimperial (cf. Gallardo et al. 2000). Entre estas evidencias, no asociadas a restos del casco de pecios, se ha mencionado la presencia de ánforas Dr. 7/11, Dr. 20 y Beltrán IIA-B para el horizonte altoimperial, y de ánforas Almagro 50/51 y vajilla ASRW para un horizonte datado entre los siglos IV-V d.C. (al que habría que sumar un importante conjunto de sesenta monedas de bronce AE2 y AE4 datadas en el siglo IV d.C. recuperadas en la misma zona en 1998-1999; cf. López de la Orden et al. 2001). Se trata por tanto de evidencias que, ligadas a pecios o a una zona de fondeadero, atestiguan la intensa utilización del paleocaño como puerta de entrada y salida a la bahía, y que permiten por tanto explicar la presencia de los productos de importación altoimperiales y tardoantiguos registrados en el Coto de la Isleta.

\section{CONCLUSIONES}

Las evidencias discutidas en los apartados precedentes permiten abrir nuevas vías de interpretación funcional y cronológica para el asentamiento de Coto de la Isleta, aún sin concretar excavaciones en extensión o estratigráficas en el yacimiento y su entorno, y asimismo para su contextualización en el conjunto del poblamiento de época romana de las áreas ribereñas del tramo meridional del caño de Sancti Petri. Avanzamos ahora en este apartado final algunas ideas esenciales que en cierta medida se han ido apuntando en los epígrafes anteriores, las cuales suponen un primer paso en la reactivación de la investigación, hipótesis por tanto que deberán ser verificadas en un futuro próximo a través de nuevas actuaciones de campo (puesto que el rápido deterioro de la zona por la erosión marina hace de estas intervenciones un elemento perentorio para el diagnóstico histórico y de conservación).

Respecto a la primera de estas cuestiones, consideramos que será necesaria una exploración más profunda para poder caracterizar funcionalmente de forma definitiva el yacimiento, puesto que las evidencias existentes plantean serias dudas respecto a su identificación inequívoca con una cetaria. La estratigrafía obtenida en nuestras visitas al yacimiento, la posición relativa de las estructuras identificadas como piletas y el pavimento musivo, así como el examen de la propia morfología de las supuestas pilas de salazón permiten cuestionar esta interpretación. De este modo, parece más probable que estas estructuras dotadas de un recubrimiento de cocciopesto correspondan a una cisterna con una cubierta plana o con bóveda de medio cañón, cuyo techo habría estado cubierto a su vez por los pavimentos del nivel inferior del edificio romano. Según sugieren las cotas relativas obtenidas en la sección estratigráfica, buena parte de esta cisterna estaría por debajo del nivel mareal actual y cubierta por los limos grisáceos de las marismas circundantes, por lo que es posible que los depósitos arqueológicos de relleno hayan quedado fosilizados bajo estos aportes recientes. En cualquier caso, esta interpretación alternativa como cisterna queda igualmente sujeta a la necesidad de una futura verificación mediante sondeos.

La erosión marina litoral, a pesar de la cercanía del muro de "vuelta afuera" de la salina, ha afectado a este tramo del yacimiento dejando al descubierto no solo la parte alta de esta posible cisterna, sino también dañando los pavimentos y muros circundantes situados más al norte, hacia el interior de la isleta. Es más, a partir de la proyección planimétrica que hemos obtenido, es posible plantear que esta dinámica erosiva ha debido destruir una parte significativa del yacimiento que se habría extendido hacia el sur, en una zona actualmente ocupada por la marisma y situada a una cota inferior. Si esta propuesta es correcta, no parece posible entonces estimar la verdadera entidad (extensión) del asentamiento en este frente meridional, ni la tipología de las estructuras que se habrían ubicado en esta parte completamente desaparecida del yacimiento. En cualquier caso, esta información resulta útil en relación con el debate sobre la altura relativa del nivel del mar en época romana y con la posible existencia de marismas antiguas ubicadas en esta zona, que hubiesen protegido al asentamiento de la dinámica costera. Consideramos que no es por el momento posible valorar este segundo supuesto, dada la ausencia de datos geoarqueológicos específicos para las marismas del entorno del caño de Carboneros; y que respecto al nivel del mar de época romana, cabe suponer que o bien este era ligeramente inferior al actual o bien la parte erosionada de la isleta es considerable, pues no resulta lógico pensar en la construcción de un edificio de las características del documentado en el Coto de la Isleta expuesto en primera línea de costa, a pocos metros de un paleocaño entonces igualmente sujeto a los temporales y efectos mareales.

Probablemente sea en el aspecto cronológico en el cual las modificaciones respecto a lo ya publicado desde los años 1990 sean menos significativas, aunque la presencia de un pequeño fragmento de ARSW D de la forma Hayes 87A aporta un indicio acerca de una fase inédita hasta el momento en la ocupación de la isleta. $\mathrm{Si}$ 
bien se trata de un elemento aislado, documentado en la zona más alejada del reborde costero del área considerada como núcleo del yacimiento, y presenta un elevado grado de desgaste superficial, su identificación permite plantear que este punto pudo seguir ocupado hasta al menos la segunda mitad del siglo $\mathrm{V}$ o inicios del VI d.C., o que como mínimo, puntualmente se dio un uso a esta isleta en dicho horizonte cronológico. Sin duda se trata de una novedad muy sugerente, que conecta con las evidencias subacuáticas recuperadas en la zona de Lavaculos (López de la Orden et al. 2001) y también con la perduración en la ocupación de yacimientos cuyos orígenes remontan también al modelo de villa romanizada tardorrepublicana, como Gallineras, al norte en la orilla contraria del caño (Díaz y Sáez 2016). Si esta ocupación tardoantigua corresponde a un uso esporádico de la isleta, quizá vinculado a la pesca, la navegación o la explotación de salinas, o si se relaciona con un asentamiento más estable (continuidad o no del evidenciado por las estructuras dejadas al descubierto por la erosión), solo será posible determinarlo en el futuro mediante catas estratigráficas que permitan determinar la relación entre estos horizontes materiales.

El conjunto de evidencias descritas hace, por tanto, que podamos relacionar los restos conocidos en la zona sur del Coto de la Isleta con un edificio vinculado a un asentamiento tipo villa, quizá de su parte urbana, si atendemos a la presencia de pavimentos de mosaico bícromo. La posible villa pudo tener una íntima relación con las actividades pesquero-conserveras y salineras, y seguramente con el tránsito marítimo a través del caño y la explotación agrícola de la propia isleta. Poca duda cabe también de que la orientación hacia el sur del edificio, en conexión visual con la desembocadura del caño de Sancti Petri (y por tanto con el templo de Hércules Gaditanus) no debe obedecer a la casualidad, y denota una relación fluida entre ambos focos de poblamiento. Como ya se ha puesto de manifiesto en muchas ocasiones en la historiografía precedente, el santuario fue también durante varios siglos después del cambio de Era un centro de culto y de actividad económica muy destacado en el occidente del Imperio, y todo su entorno debió funcionar a su vez como una zona de fondeadero y de trasiego de entrada y salida de productos desde/hacia la bahía interna. De forma análoga a lo señalado por Horozco (1598) para inicios de la Edad Moderna, el caño debió ser en época romana y tardoantigua una arteria esencial para la economía de la bahía, que además permitía enlazar a través del Iro con Asido/Asidona y las fértiles campiñas circundantes, y al mismo tiempo debió ser un epicentro para la propia pesca atunera estacional y la labra de salinas.
Por ello es posible valorar la opción de que este asentamiento pudiese identificarse con el topónimo $\mathrm{Ad}$ Herculem, citado en el Itinerario de Antonino (siglo III d.C.) y que estaría en el tramo inicial del desarrollo de la vía costera que unía Gades y el templo de Hércules Gaditano. Esta posible mansio itineraria estaría ubicada junto a la vía principal, como sugiere el uso de la construcción " $a d$ " + acusativo (Roldán Hervás 1966: 117-118; 1975; Corzo, 1992: 39-40). De ser cierta esta identificación, establecería una conexión aún más íntima entre el templo y el asentamiento localizado en la costa sur de la isleta. El acceso a este complejo durante la etapa romana debió realizarse por vía marítima, acaso desde algún embarcadero ubicado en la cercana costa continental (quizá como parte de la red de marismas/salinas y paleocaños) o desde el propio entorno del templo. No pueden excluirse sin embargo otras opciones para la localización de Ad Herculem, como por ejemplo los restos de fábricas conserveras localizados en la cercana playa de Camposoto (Sáez y Carrero e.p.).

En todo caso, cabe interpretar el yacimiento romano y tardoantiguo del Coto de la Isleta como un posible punto de paso hacia la isla gaditana, y sobre todo como un centro de interés en relación con el tráfico marítimo desarrollado a través del caño, en conexión con evidencias de centros de producción conservera, alfarera y $v i$ llae situadas en ambas orillas de la zona meridional del caño y de la ínsula gaditana (playa de Camposoto) y discutidas también en trabajos anteriores (Díaz et al. 2012; Sáez y Díaz 2012; Sáez y Carrero 2016). El paisaje en este "patio trasero" del santuario principal de Gades debía estar marcado por salinas, esteros, embarcaderos y asentamientos rurales basados en el modelo de la villa romana, que de manera continuada se distribuyeron desde esta embocadura meridional hasta la falda del Cerro de los Mártires, la conexión con el Iro, el entorno del puente-acueducto (junto al actual castillo de San Romualdo) y el área de Barrio Jarana - Puente Melchor (cf. Pemán 1959; Díaz et al. 2004; Díaz y Sáez e.p.; Sáez y Sáez 2004; Lavado 2004; Millán y Gómez 2012; Chacón 2013).

No podemos finalizar estas conclusiones sin apuntar, al menos brevemente, algunas ideas sobre el futuro de la investigación del yacimiento y de su conservación. Como se ha adelantado desde el inicio de estas páginas, la incidencia de la erosión mareal y su combinación con la frecuentación antrópica ocasional del lugar amenazan a muy corto plazo la conservación de las zonas hoy visibles de las estructuras romanas y la contextualización de los materiales muebles asociados a ellas, por lo que se impone una actuación de 
urgencia que permita documentar arqueológicamente todo este sector antes de que se produzca su pérdida total. En función de los resultados de estas actuaciones estratigráficas y en extensión, deberán articularse medidas de conservación, como la cubrición de la zona con áridos aportados o la construcción de muretes de contención que aíslen el yacimiento de la acción mareal. Estas medidas que garanticen la conservación del yacimiento podrán ir integradas con el desarrollo de un programa museográfico, y también con el planteamiento de excavaciones en extensión hacia el interior de la isleta, donde la irregularidad del terreno y de la disposición de la vegetación sugieren una mejor preservación de las estructuras romanas. Se trata de un yacimiento excepcional por su tipología, su ubicación insular en pleno caño junto al templo de Hércules $G a$ ditanus y por la secuencia cronológica que se intuye para su ocupación (o frecuentación), por lo que debería ser objeto de atención a corto plazo desde la perspectiva institucional y científica.

\section{Agradecimientos}

Para la clasificación de las ánforas y la vajilla cerámica romana se ha contado con el respectivo asesoramiento de E. García Vargas (Universidad de Sevilla) y M. C. Reinoso del Río (Museo Municipal de Villamartín, Cádiz), a los que agradecemos sus orientaciones tipo-cronológicas. Se agradece también a los revisores anónimos del artículo sus sugerencias respecto a la orientación en la interpretación de las cubetas de cocciopesto. En cualquier caso, los errores que puedan detectarse en las atribuciones y dataciones finalmente propuestas son únicamente imputables a los autores de este trabajo.

\section{BIBLIOGRAFÍA}

Alonso Villalobos, C.; Gallardo Abárzuza, M.; Garcia Rivera, C. y Martí Solano, J. (1994): "Prospecciones Arqueológicas Subacuáticas en Sancti-Petri”. Anuario Arqueológico de Andalucía 1994, Actividades Sistemáticas, Sevilla: 44-48.

Alonso, C. y Gracia, F. J. (2004): "La paleotopografía costera y el asentamiento de puertos, fondeaderos y zonas de producción del litoral gaditano durante la Antigüedad", en L. De María y R. Turchetti (eds.), Actas del I Seminario ANSER. Evolución paleoambiental de los puertos y fondeaderos antiguos en el Mediterráneo occidental: 167-195. Alicante (2003), Catanzaro, Rubbettino.

Alonso, C.; Gracia, F. J. y Benavente, J. (2004): "Las marismas, alfares y salinas como indicadores para la restitución paleotopográfica de la Bahía de Cádiz durante la antigüedad", en XVI Encuentros de Historia y Arqueología. Las industrias alfareras y conserveras fenicio-púnicas de la Bahía de Cádiz: 263287. San Fernando (2000), Córdoba, CajaSur.

Alonso, C.; Gracia, F. J. y Benavente, J. (2009): "Evolución histórica de la línea de costa en el sector meridional de la Bahía de Cádiz". Revista AtlánticaMediterránea de Prehistoria y Arqueología Social 11: 13-37. DOI: http://dx.doi.org/10.25267/Rev_ atl-mediterr_prehist_arqueol_soc.2009.v11.01

Alonso, C.; Gracia, F. J. y Menanteau, L. (2003): “Las salinas de la Bahía de Cádiz durante la Antigüedad: visión geoarqueológica de un problema histórico". Spal 12: 317-332. DOI: http://dx.doi.org/10.12795/ spal.2003.i12.13

Alonso, C.; Menanteau, L.; Navarro, M.; Mille, S. y Gracia, F. J. (2001): “Antropización histórica de un espacio natural. Las salinas de la Bahía de Cádiz”. Boletín del Instituto Andaluz de Patrimonio Histórico 35: 172-185.

Arteaga, O. y Schulz, H. D. (eds.) (2008): Geoarqueología y proceso histórico en la Bahía de Cádiz. Revista Atlántica-Mediterránea de Prehistoria y Arqueología Social 10. Cádiz, Universidad de Cádiz. DOI: http://dx.doi. org/10.25267/Rev_atl-mediterr_prehist_arqueol_ soc.2008.v10.01

Astilleros, J.M. y Garófano, R. (2003): Las costas de Cádiz desde el cielo. Cádiz, Diputación Provincial de Cádiz.

Atlante (1981): Enciclopedia dell'arte antica classica e orientale. Atlante delle forme ceramiche I: Ceramica fine romana nel bacino Mediterraneo. Medio e tardo impero. Roma, Istituto della Enciclopedia Italiana.

Bernal Casasola, D.; Montero, A. I.; Sáez Romero, A. M.; Lagóstena, J. y Lorenzo, L. (2007): "Novedades sobre la producción anfórica púnico-gaditana (ss. V-I a.C.). Avance del taller alfarero de la C/ Asteroides (San Fernando, Cádiz)", en J. Morín, D. Urbina y N. Ferreira (eds.), As Idades do Bronze e do Ferro na Península Ibérica. Actas do IV Congresso de Arqueologia Peninsular: 309-326. Faro (2004), Braga, Universidade do Algarve.

Bernal Casasola, D.; Sáez Espligares, A.; Sáez Romero, A. M.; Díaz, J. J.; Lorenzo, L. y Toledo, F. (2005): 
Carta Arqueológica Municipal. San Fernando (Cádiz). Sevilla, Junta de Andalucía.

Bernal Casasola, D. y Sáez Romero, A. M. (2006): “Infundibula gaditana. Acerca de los vasos troncocónicos perforados para filtrar garum y otros usos industriales en la Bahía de Cádiz”. Romvla 5: 167-218.

Bernal Casasola, D.; Sáez Romero, A. M.; Montero, R.; Díaz, J. J.; Toboso, E. J. y Moreno, D. (2006): “Instalaciones fluvio-marítimas de drenaje con ánforas romanas. A propósito del embarcadero del Caño de Sancti Petri (San Fernando, Cádiz)". Spal 14: 177228. DOI: 10.12795/spal.2005.114.07

Berni Millet, P. (2011): “Tipología de la Haltern 70 bética”, en C. Carreras, R. Morais y E. González (eds.), Ánforas romanas de Lugo. Traballos de Arqueoloxía 3: 80-107. Lugo, Concello de Lugo.

Bethencourt, M.; Gracia, F. J.; Del Río, L. y Benavente, J. (2011): "Los restos de naufragios históricos como indicadores de paleolíneas de costa. El caso del Fougueux (Bahía de Cádiz)", en I. Montoya, I. Rodríguez y M. J. Sánchez (eds.), Avances en Geomorfología Litoral. Actas de las VI Jornadas de Geomorfología Litoral: 47-50. Tarragona (2011), Barcelona, JMC Ofimática.

Blanco Freijeiro, A. (1985): "Los nuevos bronces de Sancti Petri”. Boletín de la Real Academia de la Historia CLXXXII-2: 207-216.

Bonifay, M. (2004): Etudes sur la céramique romaine tardive d'Afrique. British Archaeological Reports International Series 1301. Oxford, Archaeopress.

Bueno Serrano, P. y Cerpa, J. (2010): "Un nuevo enclave fenicio descubierto en la Bahía de Cádiz: el Cerro del Castillo, Chiclana". Spal 17: 169-206. DOI: http://dx.doi.org/10.12795/spal.2008.i17.08

Castillo, A.; Velázquez-Gaztelu, F. y González, M.C. (1982): Historia de los pueblos de Cádiz. Chiclana de la Frontera. San Fernando, Diputación de Cádiz.

Chacón Mohedano, C. (2013): "Nuevas estructuras arqueológicas documentadas en el yacimiento de Puente Melchor, Puerto Real, Cádiz". Mainake XXXIV: 77-94.

Cobos, L.; Muñoz, A. y Perdigones, L. (1997): “Intervención arqueológica en el solar del antiguo Teatro Andalucía de Cádiz: la factoría de salazones y la representación gráfica del faro de Gades". Boletín del Museo de Cádiz 7: 115-132.

Corzo Sánchez, R. (1992): "El templo de Hércules gaditano en época romana". Boletín del Museo de Cá$\operatorname{diz} \mathrm{V}: 37-47$.

Díaz Rodríguez, J. J.; Sáez Romero, A. M.; Montero, R. y Montero, A. I. (2004): “Alfarería romana en
San Fernando (Cádiz). Análisis del proceso productivo cerámico en el hinterland insular de Gades", en D. Bernal y L. Lagóstena (eds.), Actas del Congreso Internacional Figlinae Baeticae. Talleres alfareros y producciones cerámicas en la Bética romana (ss. II a.C.-VII d.C.), BAR International Series, 1266: 649-662. Oxford, Archaeopress.

Díaz Rodríguez, J. J. y Sáez Romero, A. M. (2016): "Gallineras - Cerro de los Mártires", en R. Hidalgo (ed.), Las villas romanas de la Bética, volumen II (Catálogo): 94-107. Sevilla, Editorial Universidad de Sevilla.

Díaz Rodríguez, J. J.; Sáez Romero, A. M. y Sáez Espligares, A. (2012): "Evidencias de un taller alfarero inédito en el territorium insular de Gades. El alfar de playa de Camposoto". Boletín Ex Officina Hispana 3: 26-29.

Expósito Álvarez J.A. (2004): Las factorías de salazón de Gades (s. II a.C.-VI d.C.). Estudio arqueológico y estado de la cuestión. Cádiz, Publicaciones electrónicas de la Universidad de Cádiz.

Expósito Álvarez J.A. (2011): "La industria salazonera de época romana. El contexto del Sinus Gaditanus", en J. J. Díaz, A. M. Sáez, E. Vijande y J. Lagóstena (eds.), Estudios recientes de Arqueología Gaditana. Actas de las Jornadas de Jóvenes Investigadores. Prehistoria \& Arqueología. BAR Internacional Series 2276: 213-233. Cádiz (2008), Oxford, Archaeopress.

Expósito Álvarez, J.A. y Bernal Casasola, D. (2016): "Coto de la Isleta (Chiclana de la Frontera, España)", en RAMPPA, Red de Excelencia Atlántico-Mediterránea del Patrimonio Pesquero de la Antigüedad (http://ramppa.ddns.net/cetaria/cotode-la-isleta) [07 noviembre 2016].

Fernández-Montblanc, T.; Bethencourt, M.; Del Río, L.; Benavente, J. y Gracia, F.J. (2016): "Study of the Fougueux wreck (1805) and the remains of the Fort Lacy (1813) as indicators of paleocoastline", en IKUWA $V$. Actas del $V$ Congreso Internacional de Arqueología Subacuática. Un patrimonio para la Humanidad: 406-418. Cartagena (2014), Madrid, Ministerio de Educación, Cultura y Deporte.

Gallardo, M.; Martí, J.; Alonso, C. y García, C. (1995): "Carta arqueológica subacuática de la Bahía de Cádiz”. Cuadernos de Arqueología Marítima 3: 105-122.

Gallardo, M.; Martí, J.; Alonso, C. y García, C. (2000): "Prospecciones arqueológicas subacuáticas en Sancti-Petri. Proyecto general de investigación de la Bahía de Cádiz". Anuario Arqueológico de Andalucía, 1995, Tomo II: 15-25. 
García Vargas, E. (1998): La producción de ánforas en la Bahía de Cádiz en época romana (ss. II a.C.-IV d.C.). Écija, Gráficas Sol.

García Vargas, E. (2010): “Ánforas béticas de época augusteo-tiberiana. Una retrospectiva”, en A. M. Niveau y V. Gómez (Coords.), Las necrópolis de Cádiz. Apuntes de arqueología gaditana en homenaje a J. F. Sibón Olano: 581-624. Cádiz, Servicio de Publicaciones de la Universidad de Cádiz.

García Vargas, E.; Almeida, R. y González, H. (2011): "Los tipos anfóricos del Guadalquivir en el marco de los envases sudhispanos del siglo I a.C. Un universo heterogéneo entre la imitación y la estandarización". Spal 20:185-283. DOI: http://dx.doi. org/10.12795/spal.2011.i20.12

García y Bellido, A. (1963): "Hércules Gaditanus". Archivo Español de Arqueología XXXVI (107-108): 70-153.

Girón Anguiozar, L. (2010): “Las cerámicas comunes del alfar romano de Puente Melchor (Puerto Real, Cádiz). Un ensayo de clasificación de las formas abiertas". Herakleion 3: 105-162.

Gracia, F. J.; Alonso, C.; Benavente, J. y LopezAguayo, F. (2000): "Evolución histórica de la línea de costa en la Bahía de Cádiz”, en J. R. de Andrés y F. J. Gracia (eds.), Geomorfología Litoral. Procesos Activos: 225-233. Madrid, Instituto Tecnológico Geominero de España.

Gracia, F.J.; Alonso, C.; Gallardo, M.; Giles, F.; Benavente, J. y López Aguayo, F. (1999): "Evolución Eustática postflandriense en las marismas del Sur de la Bahía de Cádiz". Geogaceta 27: 71-74.

Gracia, F.J.; Gallardo, M.; Giles, F.; Alonso, C.; Martí, J.; Benavente, J.; Reyes, J. y Abad, E. (1995): "Los niveles holocenos-históricos del Coto de la Isleta (Chiclana de la Frontera, Bahía de Cádiz)", en T. Aleixandre y A. Pérez-González (eds.), Reconstrucción de paleoambientes y cambios climáticos durante el Cuaternario. Centro de Ciencias Medioambientales (Serie Monografías, 3): 409-422. Madrid, CSIC.

Horozco, A. (1598): Historia de la ciudad de Cádiz. Cádiz.

Lagóstena Barrios, L. (2002): La producción de salsas y conservas de pescado en la Hispania romana (II a.C-VI d.C). Barcelona, Universidad de Barcelona.

Lagóstena, L. y Bernal, D., (2004): “Alfares y producciones cerámicas en la provincia de Cádiz. Balance y perspectivas", en D. Bernal y L. Lagóstena (eds.), Actas del Congreso Internacional Figlinae Baeticae 2003. Talleres alfareros y producciones cerámicas en la Bética romana (ss. II a.C.-VII d.C.). BAR
International Series 1266, vol. I: 39-124. Oxford, Archaeopress.

Lavado Florido, M.L. (2004): "El complejo industrial de Puente Melchor: el centro productor, la organización del espacio y su área de influencia”, en D. Bernal y L. Lagóstena (eds.), Actas del Congreso Internacional Figlinae Baeticae 2003. Talleres alfareros y producciones cerámicas en la Bética romana (ss. II a.C.-VII d.C.). BAR International Series 1266, vol. II: 473-488. Oxford, Archaeopress.

López de la Orden, M.D.; Gallardo, M. y Blanco, F.J. (2001): "Estudio numismático de monedas bajoimperiales procedentes del yacimiento subacuático de Lavaculos (Sancti Petri, Cádiz)". PH Boletín 37: 127-135.

Millán, M.L. y Gómez, M.C. (2012): "El mosaico de la villa romana de Puente Melchor. Estudio históricoartístico y tratamientos de conservación". Romvla 11: 115-136.

Pemán Pemartín, C. (1959): “Alfares y embarcaderos romanos en la provincia de Cádiz". Archivo Español de Arqueología XXXII: 169-173.

Quintero Atauri, P., (1906): "Las ruinas del templo de Hércules en Sancti Petri”. Revista de Archivos, Bibliotecas y Museos 14: 199-203.

Roldán Hervás, J. M. (1966): "Sobre los acusativos con "ad" en el Itinerario de Antonino". Zephyrus XVII: 109-120.

Roldán Hervás, J. M. (1975): Itineraria Hispana. Fuentes antiguas para el estudio de las vías romanas de la Península Ibérica (Anejo de Hispania Antiqua). Granada-Valladolid, Universidad de Granada-Universidad de Valladolid.

Sáez Romero, A. M. (2009): "El templo de Melqart de Gadir: hito religioso-económico y marítimo. Consideraciones sobre su relación con la industria conservera”, en P. Mateos, S. Celestino, A. Pizzo y T. Tortosa (eds.), Santuarios, oppida y ciudades: Arquitectura sacra en el origen y desarrollo urbano del Mediterráneo Occidental. Anejos de AEspA XLV: 115-130. Mérida (2005), Madrid, CSIC-IAM.

Sáez Romero, A. M.; Bernal, D.; García Vargas, E. y Díaz, J. J. (2012): "Ramon T-7433 (Costa de Baetica)", en Amphorae ex Hispania. Paisajes de producción y de consumo (http://amphorae.icac.cat).

Sáez Romero, A. M. y Carrero Ramírez, F. (2016): "Arqueología de las marismas en el tramo meridional del Caño de Sancti Petri (Bahía de Cádiz, España). Actualización de datos y perspectivas geoarqueológicas", en IKUWA V. Actas del V Congreso Internacional de Arqueología 
Subacuática. Un patrimonio para la Humanidad: 419-421. Cartagena (2014), Madrid, Ministerio de Educación, Cultura y Deporte.

Sáez Romero, A. M. y Carrero Ramírez, F. (en prensa): "De Torregorda a Sancti Petri. Apuntes sobre la evolución de la línea costera y sus implicaciones para el análisis de la industria pesquero-conservera gaditana de la Antigüedad", en S. Almisas, A. Barrena, A. Doyague y A. Moreno (eds.) Nuevos enfoques interdisciplinares para el estudio de la Prehistoria y Protohistoria en Andalucía. Colección Historia y Arte. Cádiz, Editorial Universidad de Cádiz.

Sáez Romero, A. M., y Díaz Rodríguez, J. J. (2012): "Entre tierra y mar, entre lo púnico y lo romano. Adaptaciones económicas y territoriales en un medio cambiante: algunas notas sobre paleogeografía y sistemas de explotación del hinterland insular de Gadir/Gades", en B. Mora y G. Cruz (coords.), La etapa neopúnica en Hispania y el Mediterráneo centro occidental: identidades compartidas. Serie Historia y Geografía 246: 259-300. Sevilla, Universidad de Sevilla.

Sáez Romero, A. M. y Díaz Rodríguez, J. J. (2014): “El alfar gaditano de El Palomar (El Puerto de Santa María, Cádiz). Aportaciones a su secuencia de actividad y sus producciones", en R. Morais, A. Fernández y M. J. Sousa (eds.), As produções ceramicas de imitaçao na Hispania. Actas del II Congreso Internacional de la SECAH, tomo 1: 179-197. Braga (2013), Porto, SECAH.

Sáez Romero, A.M.; González Cesteros, H. e Higueras-Milena Castellano, A. (2016): “Una aportación al estudio del comercio marítimo antiguo gaditano a partir de un conjunto de ánforas halladas en aguas del área de La Caleta (Cádiz). Onoba. Revista de Arqueología y Antigüedad 4: 3-18.
Sáez Romero, A. M. y Montero, A. I. (2007): "La secuencia diacrónica de la Isla de León en la Antigüedad a través del Cerro de la Batería (San Fernando, Cádiz)", en J. Morín, D. Urbina y N. Ferreira (eds.), As Idades do Bronze e do Ferro na Península Ibérica. Actas do IV Congresso de Arqueologia Peninsular: 387-408. Faro (2004), Braga, Universidade do Algarve.

Sáez Romero, A. M.; Montero, A. I. y Díaz, J. J. (2005): "Nuevos vestigios del santuario gadirita de Melqart en Sancti Petri (San Fernando, Cádiz)", en J. Jiménez y S. Celestino (coords.), El Periodo Orientalizante. Actas del III Simposio de Arqueología de Mérida. Protohistoria del Mediterráneo occidental. Anejos de AEspA XXXIII: 873-878. Mérida (2003), Mérida, CSIC-IAM.

Sáez Romero, A. M.; Montero, R.; Montero, A. I.; Sáez, A. y Díaz, J. J. (2004): “Anotaciones al recorrido de las vías Augusta y Heraclea a su paso por San Fernando (Cádiz). Novedades arqueológicas y paleogeográficas". Antiquitas 16: 105-119.

Sáez Romero, A.M. y Sáez Espligares, A. (2004): "Control arqueológico de urgencia realizado en el solar de la C/ Albardonero n ${ }^{\circ} 24$. San Fernando (Cádiz)". Anuario Arqueológico de Andalucía/2001, vol. 3 (1): 93-98.

Vallespín, O. (1985): “Carta Arqueológica de la Caleta", en VI Congreso Internacional de Arqueología Submarina: 59-74. Cartagena (1982), Madrid, Ministerio de Educación, Cultura y Deporte.

Vallespín, O. (1986): “The Copper Wreck (Pecio del Cobre)". The International Journal of Nautical Archaeology and Underwater Exploration 15.4: $305-$ 322. DOI: 10.1111/j.1095-9270.1986.tb01155.x

Vallespín, O. (2004): El Camino del Arrecife en Cádiz. El Miliario Extravagante, Anexo 6. Cortes de la Frontera, G. Arias. 